\title{
A biosystematic basis for pelagic biodiversity*
}

\author{
S. van der Spoel \\ Institute of Systematics and Population Biology, University of Amsterdam, P.O. Box 94766, 1090 GT \\ Amsterdam, The Netherlands
}

Keywords: Biodiversity, diversity calculation, ecology, pelagic, phylogeny

\begin{abstract}
Biodiversity can be considered to be a human appreciation of the biological entity diversity. Diversity can be expressed numerically on the basis of taxa found, but it can also be expressed as the contribution of a specimen to the diversity, for which a formula is proposed. Diversity is the sum of the taxonomic or numerical diversity, and the ecological, genetical, historical, and phylogenetic diversity. Moreover, each group, or larger taxon, has its own characteristic diversity. These types of diversity are considered separately. One formula is tentatively proposed to calculate the overall diversity. Diversity in nature is variable, which is demonstrated in a diagram for comparison with societyinduced diversity changes. Diversity in the pelagic fluctuates differently from biomass fluctuations, but biomass fluctuations also influence diversity fluctuations. From a scientific and an environmental preservation point of view, special studies should be devoted to the Indo-Malayan neritic and oceanic waters, the neritic temperate and subtropical waters, the tropical waters in general, and especially to the Atlantic and Pacific Central waters.
\end{abstract}

\section{Résumé}

La biodiversité peut être considérée comme une appréciation humaine de l'entité biologique "diversité". La diversité peut être exprimée sur la base du nombre de taxa trouvés, mais aussi comme mesure dans laquelle un exemplaire contribue à la diversité: pour ceci une formule est proposée. La diversité est la somme de la diversité taxonomique (numérique), écologique, génétique, historique et phylogénétique. En outre, chaque groupe ou taxon assez grand a sa propre diversité caractéristique. Ces types de diversité ont été considérés séparément. Une formule est proposée pour calculer la diversité globale. Un diagramme servira pour une comparaison entre la variabilité de la diversité dans la nature et les changements de la diversité provoqués par la société humaine. Les fluctuations de la diversité dans le pélagial diffèrent des fluctuations dans la biomasse, mais les fluctuations dans la biomasse ont aussi une influence sur les fluctuations de la diversité. Du point de vue scientifique et de la préservation de l'environnement, des études spéciales devraient être dévouées aux eaux océaniques et néritiques indo-malaises, ainsi qu'aux eaux néritiques tempérées et subtropicales, aux eaux tropicales en général, et spécialement aux eaux centrales de l'Atlantique et du Pacifique.

\section{Introduction}

Diversity is such a basic concept that in speaking of pelagic diversity, one must also make some general remarks. The organisms living in the open ocean consist of plankton and nekton, floating with the currents over enormous distances and dispersed over depths averaging $3500 \mathrm{~m}$. Despite the large dimensions of the ocean which covers more than $70 \%$ of the earth surface, its biological diversity in general is small: only at most $40 \%$ of all known species are living in the ocean (Pierrot-Bults \& Van der Spoel, 1979). Ocean life is on the one hand very sensitive to climatic changes, as shown during geological history. On the other hand it is ocean life that largely determines atmospheric conditions through its influence on the atmospheric gases. By the year $2000,60 \%$ of the human world population will be living in or depending on the coastal zone (Lasserre,

* Paper presented at the SCOR WG 93 workshop on Pelagic Biogeography, Amsterdam, 30 Aug.-1 Sept. 1993. 
1992), where a major food supply will come from the pelagic. Last but not least, ocean pollution usually has dramatic effects over greater areas than terrestrial pollution.

Thus, evidently pelagic diversity needs special attention, focusing on the existing diversity that needs to be maintained and the reduced diversity that needs to be restored. Attention should be given to studies of the natural fluctuations in diversity, which must be understood before society-induced changes can be detected. Here the time scale becomes important, e.g., the question of how long does it take to restore the environment and over what period should preservation measures be taken.

First we have to define what the diversity is from a human point of view and from a biological point of view. Can we formulate diversity exactly, and how can we measure it?

\section{What is biodiversity?}

A scientific term should have a definition. A political term is valid already when it has a long list of synonyms although no definition. Who coined the term biodiversity? A politician I am afraid, though many scientists have advocated the use of the term biodiversity (Wilson, 1992). Combining "bio" from biology, the study of life, with "diversity" one of the most typical characters of life - seems overdone, since without life there is no diversity and without diversity, no life. Humans need a healthy, living and diverse world and like to name this life in an attempt to have power over it. On the other hand, humans are afraid of the delicate wonder of the living world and look for euphemisms like biodiversity to indicate this wonder.

Diversity has also a pure biological content (we will not use further the term biodiversity). It is the always variable presentation, in time and space, of the phenomenon "life". The science of systematics is entirely devoted to the study of the forms in which life is present and to the creation of order in the seemingly chaotic biota. Systematics is the science that can describe and handle the diversity of this chaos by determining the principles underlaying this chaos.

There are thus two approaches to diversity possible, one starting with the human being full of fickleness and one dealing with the very variable biological specimens.

In this paper the human concern about diversity and the needs for diversity will be considered first; the diversity crisis can show the value of diversity. Secondly, the biological value for diversity is derived, first by considering the higher taxa and later by considering the species. The relation of abundance and biomass to diversity is considered before trying to calculate the diversity based on individual specimens of species. To this numerical diversity the genetic, phylogenetic, historical, and ecological diversity is added to arrive at one formula to express diversity.

As diversity is linked with an area, the geographic distribution of diversity is considered. Finally, the taxon is briefly discussed as a diversity carrier, before making some remarks on more or less endangered areas in the open ocean.

\section{A human concept}

Human concern about diversity is not a recent phenomenon. The bible tells us of the Ark of Noah, the first global protection of diversity. The principle is well described:

\footnotetext{
"And of every living thing of all flesh, two of every sort shalt thou bring into the ark, to keep them alive with thee; they shall be male and female"' (Gen. 6-19).

"Of every clean beast thou shalt take to thee by sevens, the male and his female: and of beasts that are not clean two, the male and his female"' (Gen. 7-2).

"Of fowls also of the air by sevens the male and his female; to keep seed alive upon the face of all the earth" (Gen. 7-3).

"And they went in unto Noah into the ark, two and two of all flesh, wherein is the breath of life" (Gen. 7-15).
}

Thus populations of all species, their reproductive ability, and in case the species are useful also their variability, should be protected to preserve diversity on earth and to be used by society. Clearly we 
should not only take care of the useful species; also those seemingly unimportant to society should be preserved. Diversity seems also to indicate harmony of organisms in equilibrium with each other. Certainly this early environmental wisdom of the bible concerns diversity, protected to form a continuous source of food and health.

\section{What kind of diversity do we need?}

It is probably easier to detect what kind of diversity is not needed, viz. the diversity that is no longer useful, neither for nature nor for society. Too strong a protection could freeze the existing diversity so that the continuous process of natural diversification and evolution would be stopped. Such a frozen diversity is useless, and a protection that prevents society from making use of the organisms that contribute to the diversity has no value either. In the pelagic realm, no examples can be found of this "freezing", but animal stocks in zoos and the terrestrial communities in wild preservation areas are examples of frozen diversity that have no potential for further development as long as the managed situation endures.

What do we need to live and to provide our offspring with a world that is healthy, living and diverse, thus evolving and diversifying? The minimum diversity required in the ocean is the diversity of the organisms that keep the atmosphere and hydrosphere in an equilibrium (e.g., $\mathrm{O}_{2}$ production; $\mathrm{CO}_{2}, \mathrm{Ca}$ and nutrient absorption, neutralization of river output), provide biological stocks for fisheries, and maintain an aesthetic environment.

We know that changes in solar radiation (for a recent model see: Caldeira \& Kasting, 1992) and human activities will change the composition of the atmosphere, biosphere, and hydrosphere, which form an interconnected system (Lovelock \& Whitfield, 1982). So we may even think of increasing or changing diversity to cope with problems of atmospheric changes. Genetic manipulation and special programmes to generate species and ecosystems especially equipped to maintain the atmosphere in a good condition may be necessary in the future.
For certain, it is dangerous to manipulate diversity, but it may be more dangerous to live in a poisonous atmosphere or under abiotic conditions. There may come a moment when we have the choice only between two such equally bad possibilities!

For the long term, the care of diversity is a management problem. For the short term, it is a preservation problem. This portrays a conflicting situation as preservation introduces a static system and management a dynamic system. As society is usually more involved in short time profit than in long term profits, very possibly society will create, in the future, an insurmountable problem: a large scale diversity crisis due to irreversible fixation of present-day diversity due to preservation activities. Irreversible fixation in the pelagic realm is not expected to be possible at present, but in other realms it may become a real problem.

\section{What is a diversity crisis?}

A diversity crisis is caused by accumulation of irreversible changes in our environment - a frightening phenomenon as it causes "the accelerating rate of extinction of species"' (Nelson \& Ladiges, 1990). The dramatic shift in species composition of the Mediterranean (Kouwenberg \& Razouls, 1990) and the mass mortalities (Weinberg, 1992) are indications of a crisis in this enclosed basin. In other isolated basins, diversity crises are also reported. In the North Sea, Baltic and in various estuarine areas, crises are reported to have been caused by fisheries activities, marine and river pollution, off-shore activities, and transport accidents. Such crises, however, are rare in the open ocean as the "irreversible" change is here more difficult to generate by human activities. The mass extinctions at the end of the Cretaceous, also a diversity crisis produced by nature, however, show that open ocean crisis is indeed possible. Polluting the atmosphere on a global scale, affecting ocean temperature and insolation, may cause just such a comparable crisis.

Red tides and El Niño effects can be considered crises, but they are ecological crises from which we recover after some time, usually without changed 

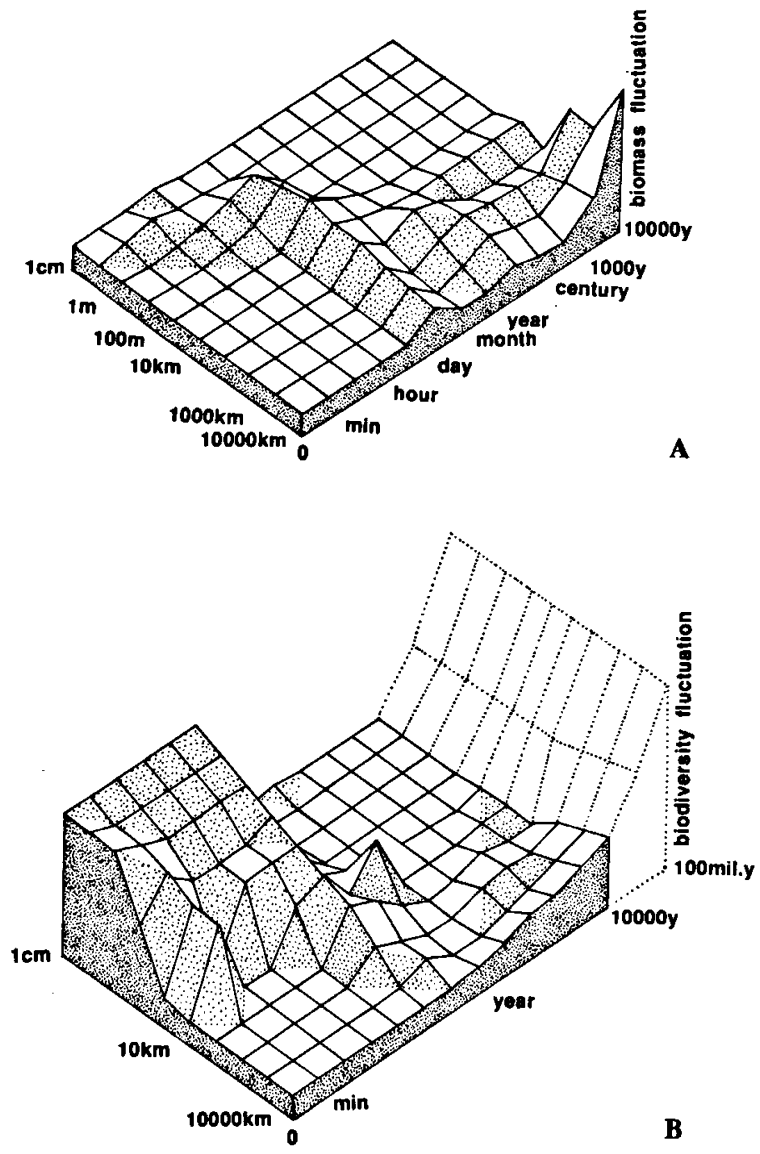

Fig. 1. A, Biomass variability simplified after the Stommel's diagram by Haury et al. (1977). B, Diversity variability at the species level. Diversity due to evolution takes place at larger time scales and is added in the dotted area; space on y-axis, time on $\mathrm{x}$-axis, variability on $\mathrm{z}$-axis.

diversity. The bloomings of toxic algae due to human-induced physicochemical changes in the environment are ecological crises from which nature recovers, as the diversity is changed only temporarily. Though the diversity in the environment has a clear value for society, this value cannot be calculated directly. The value is also dependent on the development of diversity in the future, which depends on the ability of the gene pool to generate the coming diversity from its present diversity. For this reason one can only "predict" a value for society of biological diversity. For calculations one is dependent on biological values, to which one can, of course, connect an "appreciation" of its worth to society as a derived value.

\section{A biological value}

Diversity may be viewed in the first instance as an expression of the biomass or of the species composition. Without biomass, there is no diversity, while some biomass means some diversity. But does a large biomass indicate large diversity? The biomass diversity is frequently studied. The Stommel's model as used by Haury et al. (1977) shows the biomass variability as a function of time and space (Fig. 1A). The species composition or diversity can be presented also in a Stommel's diagram (Fig. 1B). It is easily seen that large biomass variability is linked with low diversity fluctuation and vice versa, which from an ecological point of view is completely logical. This probably also explains why Cohen (1986) came to the conclusion "The latitudediversity-biomass relationship is not clear". In the time/space area of one centimetre to one kilometre and seconds to one month, there is a large variability in diversity due to physical parameters such as currents and waves, seasonal changes, diurnal and seasonal migrations, and seasonal species successions. In the area of 10 years and $10 \mathrm{~km}$ there is a separate maximum of variation in diversity due to physical variability of the type giving rise to El Niño and shifts of major current patterns. These relatively "unstable" time/space areas are probably less sensitive to human influence than the areas without variability.

Diversity has so far been treated in this paper as a relative and somewhat subjective concept. Purely scientifically, without anthropocentric interpretation, diversity can, however, also be given a value as will be shown.

The diversity in the ocean is small when the species level is considered, but when considering the phylum or subphylum level, diversity is extremely high (cf. May, 1992: table 2). Nearly all (sub)phyla are represented in the ocean, and some 14 like the Chaetognatha and Tunicata are endemic to it. Therefore one has to distinguish between: (a) higher taxa diversity related to families and higher 
taxa, (b) the species diversity, a combination of species and genera as genera can be considerd to be based on the species diversity, and (c) the subspecific diversity. The question: "Why not consider taxa in general as units, and embrace the full measure of biodiversity?" by Nelson \& Ladiges (1990) could be answered positively, but probably the taxa at different levels are also of different nature, so that one may better treat them separately in first instance.

\section{Higher taxa diversity}

The higher taxa diversity is a measure of importance mainly when considering large geographic areas. For example, it is not interesting to know the higher taxa diversity for a city park as the species diversity is more indicative of such a place. In the ocean, different higher taxa diversities can be expected in different large biotopes like the benthic, pelagic, oceanic, and neritic biotopes. In tropical and cold waters, differences can be expected at the family and order level (see Van der Spoel \& Heyman, 1983). These differences between the biotopes in the ocean are still very small when I express higher taxa diversity $(D)$ as the sum of the number of families $\left(N_{\mathrm{f}}\right)$, orders $\left(N_{\mathrm{o}}\right)$ and classes $\left(N_{\mathrm{c}}\right)$ divided by the surface size of the biotope $\left(B_{\mathrm{s}}\right)$ :

$$
\text { Dhigher taxa diversity }=\left(N_{\mathrm{f}}+N_{\mathrm{o}}+N_{\mathrm{c}}\right) / B_{\mathrm{s}}
$$

\section{Species diversity}

The species diversity is evidently dependent on the species concept used, and in discussing diversity of biogeographic areas, the geographic component in the concept should be stressed. In the definition: "species are groups of natural populations which actually or potentially reproduce and which do not reproduce with other such groups"' (Mayr, 1963), the terms "natural populations" and "potentially" should be given attention. For example, should a population of a Pacific species living in the Atlantic due to transport by ships or to aquaculture be considered an abnormal, not-natural population, as is usually done? Should a completely disjunct distribution in the north and south polar sea, or in the tropical Atlantic and tropical Indian Ocean, be considered a single species distribution, as is frequently done? It is easily seen that it is impossible to answer both questions with either yes or no. So it is here proposed for the sake of argument to answer the first question with yes and the second with no. Thus one can no longer give great value to "potential" in the definition, but will have to lay stress on "natural populations" and "which do not reproduce with other such groups".

A species as defined above still can be monotypic, polytypic, or polymorphic. Does this variability contribute to diversity, and has it to be preserved? This question is discussed later in the sections on genetic diversity and phylogenetic diversity; for the moment the species will be treated only as a well limited, not variable taxon.

Abundance of species and diversity - As we have seen that diversity fluctuations usually are different, and mostly even opposite, to biomass ( = abundance) fluctuations, it is worth noticing that (1) taxonomic groups tend to be represented by abundant and rare species, (2) groups are composed of diverse and less diverse subgroups, (3) within a taxon always occur a number of less related taxa and a number of closely related taxa, and (4) groups are represented in some areas by few and in other areas by many species. In diversity studies, one should always mind these four natural diversity phenomena.

Taxonomic groups tend to be represented by both abundant and rare species, and there seems to be a rule determining the ratio abundant/rare species in nature. In each group, many rare species are found, moderate numbers of common and very common species and low numbers of very abundant species. In Fig. 2 this distribution is given for species of Myctophidae and Hydromedusae in the North Atlantic. This frequency distribution seems to be fractal in nature and can be described with a formula like $N(x)=a x^{-b}$.

Groups are composed of a range from diverse to less diverse subgroups, and here also a natural rule seems to determine the diversity of groups in a 


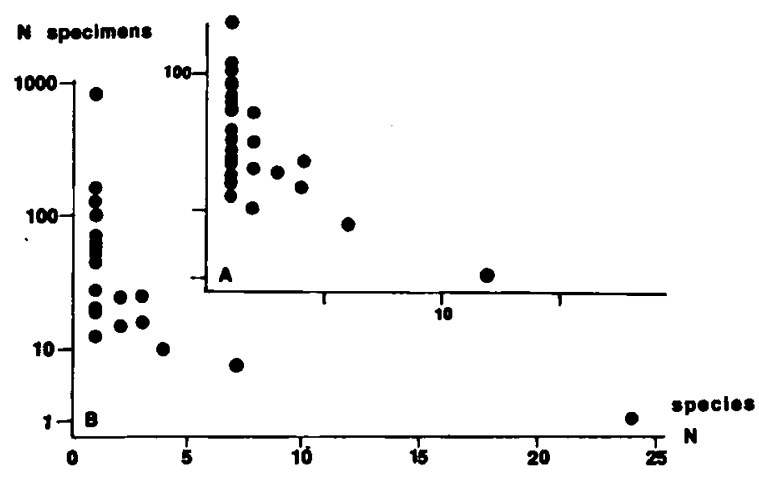

Fig. 2. Number of specimens for species of Myctophidae (A) and Hydromedusae (B) in the North Atlantic Ocean. Number of species along the $x$-axis, number classes for specimens along the $y$ axis in logarithmic scale.

taxon. In Fig. 3 the number of species per genus is given in relation to the genera in pelagic molluscs, nemerteans, siphonophores, and myctophids. In these groups many genera with few species are found, moderate numbers of genera with a moderate number of species, and low numbers of very diverse genera. This phenomenon seems to be similar for all animals groups, as discussed by Minelli et al. (1991). A formula: $N(x)=a x^{-b}$ is proposed by these authors tor characterizing the distribution of within-group diversity. The values of index $a$ for pelagic molluscs, nemerteans, siphonophores, and myctophids are $10,20,30$, and 10 , respectively; for the index $b$ the values are $0.9,1.5,1.4$, and 0.7 , respectively. In Fig. 3 this $N(x)$ function is represented by line "a". It is evident that these four groups each have their own typical diversity. Notice that this formula would also explain well the distribution of rare and abundant species in nature, as in both cases the distribution is of the same fractal type.

If the above statements are valid, a number of less closely related taxa and a number of closely related taxa occur in a taxon always in a certain relation. Fig. 4 shows a cladogram based on 54 hypothetical species with 7 characters each with two character states distributed over the species at random. In this randomized cladogram, one can distinguish that above a certain level $70 \%$ of the groups are composed of few species. This $70 \%$ level is indicated by line " $x$ ".

It is well known that each particular group (say

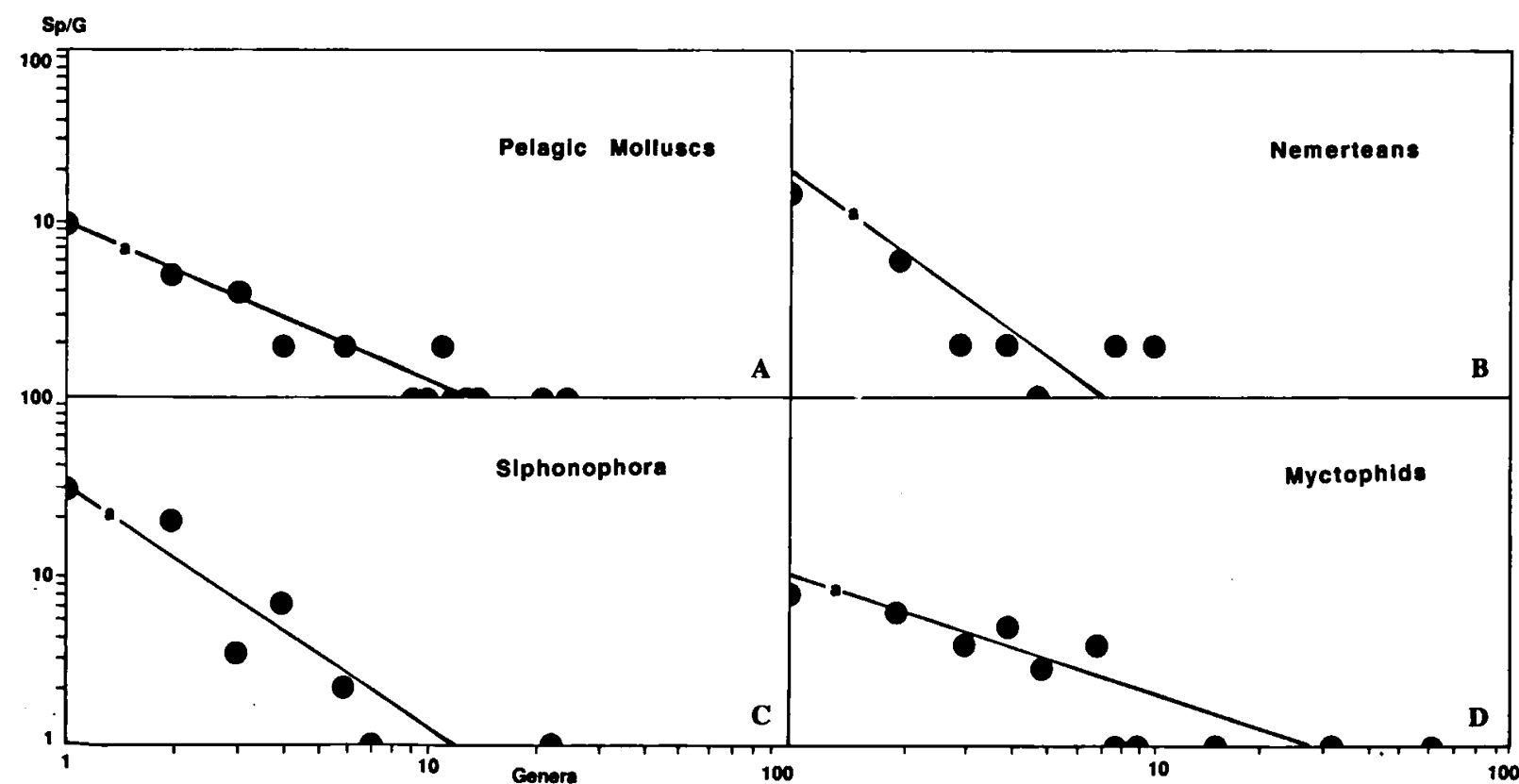

Fig. 3. The number of species per genus in the pelagic molluscs Pteropoda and Heteropoda (A), nemerteans (B), siphonophores (C), and myctophids (D). Genera on $x$-axis, species per genus on $y$-axis both logarithmic, $a=$ the line of the formula $N(x)=a x-b$ after Minelli et al. (1991). 


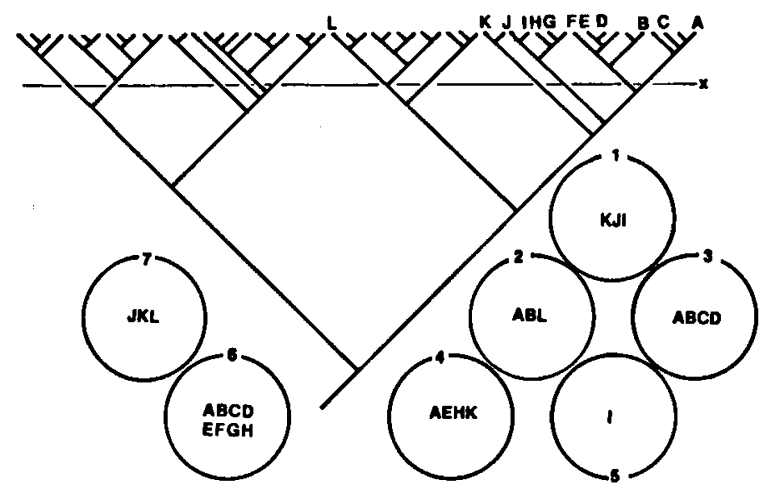

Fig. 4. Cladogram for 54 hypothetical species with 7 characters distributed totally at random over the species to show the natural occurrence (e.g., above the line $x$ ) of taxa with many and with few species. In the circles the areas are indicated where the species $A$ to $L$ are found to demonstrate that each area has a different phylogenetic diversity.

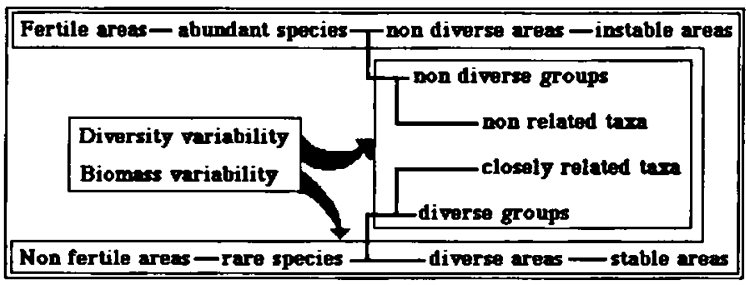

Fig. 5. Diagram of the relation of biomass and diversity fluctuations with diversity in groups, species, and areas. For explanation see text.

pelagic molluscs) shows areas with few species (e.g., South Indian Ocean) and areas with many species (e.g., North Indian Ocean). The more stable biotopes tend to show higher diversities.

As we have shown that diversity and biomass show an inverse fluctuation (e.g., biomass tends to be low in areas with high diversity), it is clear that groups with abundant species, groups with less diverse subgroups, groups with less related taxa, and areas with few representatives of a group should be treated differently from groups with rare species, groups with diverse subgroups, groups with closely related taxa, and areas with many species of a group. This is shown in Fig. 5, where the relation between these phenomena and variability in biomass and in diversity is given.

The body size of species is not considered here, as good data on body size of species are usually not

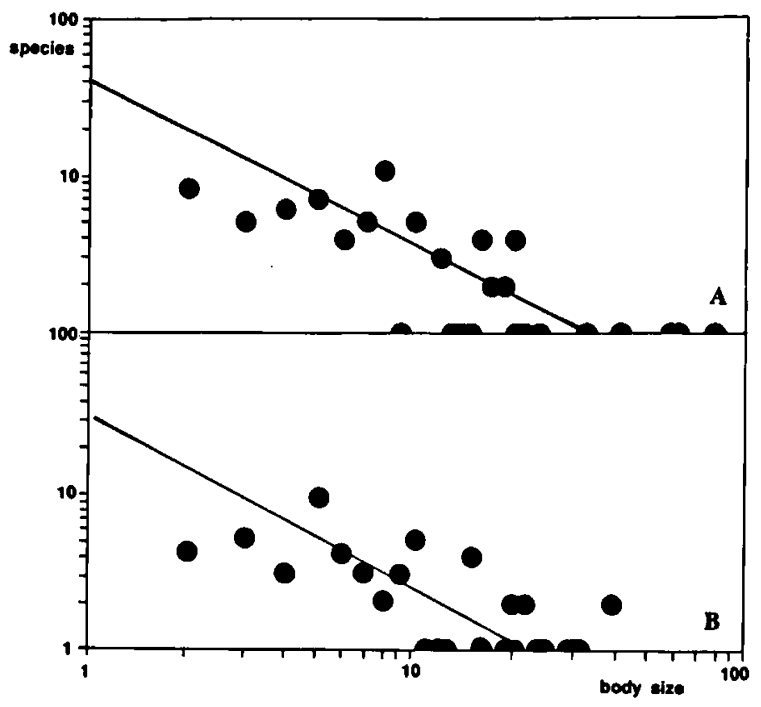

Fig. 6. Maximum body size (mm) of species for Gymnosomata (A) and Thecosomata (B) on $x$-axis, and number of species with these sizes on $y$-axis (both logarithmic) (own data).

available. However, when length in the thecosomatous or gymnosomatous pelagic molluscs is taken as an indication of body size, a distribution of this value is found for these groups that is comparable to the distribution of abundance or of diversity. Thus this also gives a distribution following the $N(x)=a x^{-b}$ formula of non-linear character given by Minelli et al. (1991) (Fig. 6). The value of $a$ for Thecosomata and Gymnosomata is 30 and 40 , respectively, and for $b$ it is for both 1.1.

Abundant species will fluctuate with biomass, thus in numbers, differently from rare species, and so will probably also the larger and smaller species.

The most abundant species are not always the species of the most diverse genera, and the rare species are not always the species of genera with few species. Limacina retroversa (Fleminger, 1823) and Styliola subula Quoy \& Gaimard, 1827 are very abundant over their whole range, but the first is a member of a diverse genus and the latter of a monotypic genus. Clio chaptali Gray, 1850 and Laginiopsis trilobata Pruvot-Fol, 1922 are both always rare but again the first is a member of a very diverse genus and the latter of a monotypic genus. The abundance and diversity fluctuations are non-parallel or unrelated processes. A further study of the charac- 


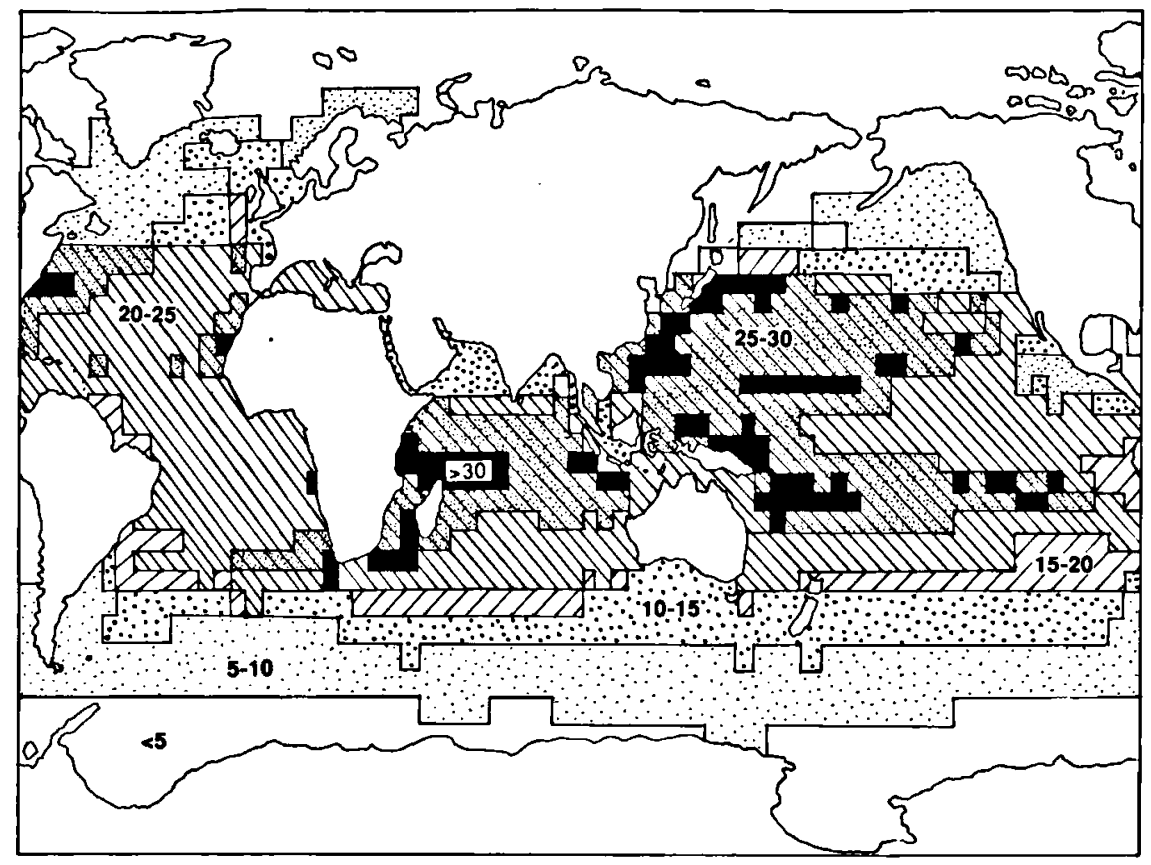

Fig. 7. Euphausiid distribution given as numbers of species (in classes of 5) per $5^{\circ}$ square (after Reid et al., 1976).

ters mentioned above for taxa in relation to biomass and diversity is highly recommended.

\section{Diversity calculation}

The diversity can be expressed in the most simple way by giving the numbers of species of a taxon occurring in different areas. In Fig. 7 the numbers of euphausiids are given per $5^{\circ}$ square after Reid et al. (1976). This kind of presentation gives only information on the biogeography of a group. So it is clear from Fig. 7 that euphausiids mainly occur in Central waters and in the Indo-Malayan area, which is expected (cf. Van der Spoel et al., 1990). Combining groups and dividing the ocean in "natural" subareas, like basins and current systems for presenting the numbers of species, gives information on species richness (Fig. 8). But this is again mainly a representation of biogeography, though it is less dependent on one group.

The diversity of a fauna or in a sample can be calculated; e.g., the dominance vs. diversity formula $(D m / D v$, see below) is frequently used. This gives more information on real diversity. However, most calculations fail to indicate the contribution of each single species to the diversity. In an attempt to distinguish between more and less diverse water masses, a formula was developed (Van der Spoel \& Bleeker, 1991) to calculate the contribution of each species to the diversity. This formula may be of value to evaluate diversity as well.

This formula is based on the assumption that a species has no value for diversity when it does not contribute to the level of diversity of the fauna and to the quality of diversity by showing a certain abundance. The importance of a species in a fauna is thus greater when its distance from the point of zero diversity and zero abundance is greater. This is expressed in the formula:

$$
B^{\prime}=\left(D^{2}+C^{2}\right)^{0.5}
$$

Here $B^{\prime}$ is the diversity value of the species for the fauna or sample in which it is found, $C$ is the value that a species adds to the quality of the fauna by its abundance, and $D$ is the value a species adds to the quality of the fauna by its contribution to diversity. 


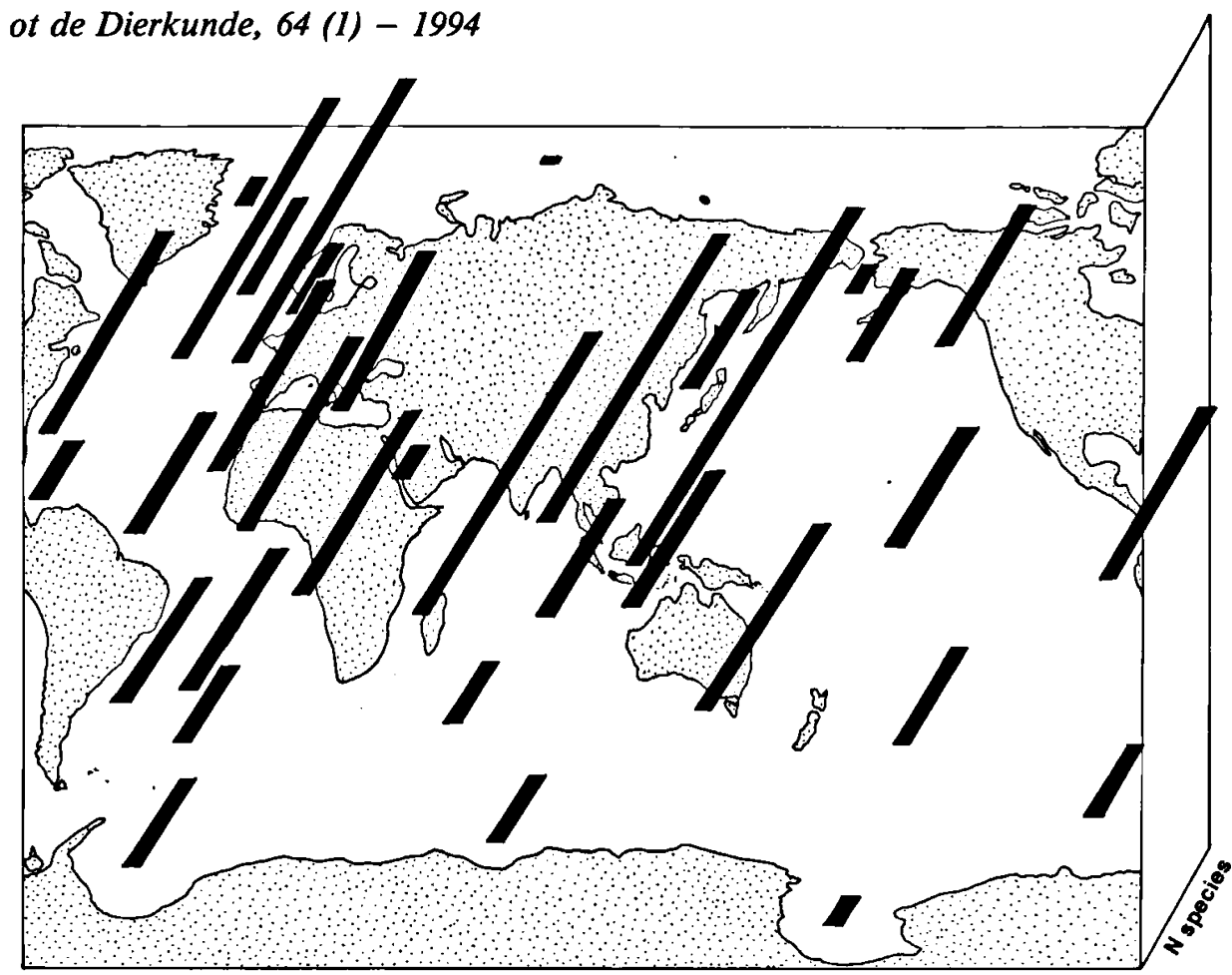

Fig. 8. Total number of species of Pteropoda, Heteropoda, and Hydromedusae found in the different ocean basins (own data; scale arbitrary).

The value $C$ of a species is dependent on the numbers of specimens relative to the abundance of that species in other samples and on the total number of species in the sample relative to that number in other samples. Thus:

$C=100 \times\left(F \times N^{\prime}-\Sigma N^{\prime}\right) /\left[\left(F \times N_{\text {max }}^{\prime}-\Sigma N^{\prime}\right) \times F / F_{\max }\right]$

Here $F$ is the number of species in the sample, $N^{\prime}$ is the logarithm of the number of specimens +1 of the species, $N^{\prime}{ }_{\max }$ is the logarithm of the number of specimens +1 of the most abundant species in the sample, and $F_{\max }$ is the number of species in the most species-rich sample.

The value of $D$ of a species in a given sample is dependent on the number of specimens in the sample, but relative to the number of the samples in which the species is found and relative to the number of species found in other samples. Thus:

$$
D^{2}=\left(1+A_{\max }-A\right)^{2} \times(1+M-A) \times N^{\prime}
$$

Here $M$ is the total number of samples in the study,
$A$ is the number of samples in which the species is found, and $A_{\max }$ is the maximum value of $A$ for the series of samples studied.

The conceptual advance is that with the formula $B^{\prime}=\left(D^{2}+C^{2}\right)^{0.5}$ the contribution of each separate species to the diversity becomes visible in a sample or fauna. This is not the case in the classical approaches of diversity as shown in the examples below. As $B^{\prime}$ is usually high, it is represented as $B^{\prime} / 100$ for comparison with other indexes. The actual influence of the numbers of specimens is suppressed by using $\log N$; the same formula can also be used with $N$ (the actual number of specimens) by replacing $\log N$ when the influence of the number of specimens of each species should become better visible. When $N$ instead of $\log N$ is used, the diversity index is called $B$ instead of $B^{\prime}$ (for an example see Table I: line $B / 100, B^{\prime} / 100$ and the blocks $B$ and $B^{\prime}$ ).

The dominance/diversity formula is expressed as: 
Table I. Data set for variable faunas (hypothetical collection of 10 species and 12 samples).

\begin{tabular}{|c|c|c|c|c|c|c|c|c|c|c|c|c|c|}
\hline species & $\mathbf{a}$ & $\mathbf{b}$ & c & d & e & $\mathbf{f}$ & g & $\mathbf{h}$ & $\mathbf{i}$ & $\mathbf{j}$ & $\mathbf{k}$ & 1 & $\begin{array}{c}\text { samples } \\
\text { A }\end{array}$ \\
\hline \multicolumn{14}{|l|}{ Data } \\
\hline I & 5 & 5 & 5 & 5 & 5 & 5 & 0 & 4 & 8 & 0 & 1 & 1 & 10 \\
\hline II & 5 & 4 & 3 & 2 & 0 & 20 & 6 & 5 & 10 & 0 & 1 & 1 & 10 \\
\hline III & 1 & 2 & 3 & 4 & 2 & 0 & 5 & 7 & 14 & 0 & 1 & 1 & 10 \\
\hline IV & 0 & 6 & 7 & 8 & 6 & 3 & 3 & 4 & 8 & 3 & 3 & 1 & 11 \\
\hline $\mathbf{V}$ & 0 & 0 & 5 & 1 & 7 & 2 & 25 & 3 & 8 & 4 & 4 & 1 & 10 \\
\hline VI & 0 & 0 & 0 & 20 & 0 & 0 & 10 & 1 & 6 & 1 & 1 & 1 & 7 \\
\hline VII & 0 & 0 & 0 & 0 & 0 & 0 & 0 & 7 & 14 & 1 & 1 & 1 & 5 \\
\hline VIII & 0 & 0 & 0 & 0 & 0 & 0 & 0 & 8 & 16 & 1 & 1 & 1 & 5 \\
\hline IX & 0 & 0 & 0 & 0 & 0 & 0 & 0 & 12 & 24 & 2 & 2 & 1 & 5 \\
\hline $\mathbf{X}$ & 0 & 0 & 0 & 0 & 0 & 0 & 0 & 19 & 18 & 23 & 23 & 2 & 5 \\
\hline$F$ & 3 & 4 & 5 & 6 & 4 & 4 & 5 & 10 & 10 & 7 & 10 & 10 & 11 \\
\hline$\Sigma N$ & 11 & 17 & 23 & 40 & 20 & 30 & 49 & 70 & 126 & 35 & 38 & 11 & \\
\hline$N \max$ & 5.0 & 6.0 & 7.0 & 20.0 & 7.0 & 20.0 & 25.0 & 19.0 & 24.0 & 23.0 & 23.0 & 2.0 & \\
\hline$F \max$ & 10 & $A \max$ & 11 & $M$ & 12 & & & & & & & & \\
\hline \multicolumn{14}{|l|}{$B$ values } \\
\hline $\boldsymbol{B}$ & 31.0 & 18.8 & 11.4 & 10.8 & 7.7 & 11.1 & 0.0 & 25.9 & 41.5 & 0.0 & 15.0 & 11.6 & \\
\hline $\boldsymbol{B}$ & 31.0 & 9.0 & 33.9 & 21.6 & 0.0 & 42.9 & 15.1 & 18.4 & 25.3 & 0.0 & 15.0 & 11.6 & \\
\hline $\boldsymbol{B}$ & 60.1 & 51.7 & 33.9 & 13.9 & 60.2 & 0.0 & 17.6 & 9.2 & 17.9 & 0.0 & 15.0 & 11.6 & \\
\hline $\boldsymbol{B}$ & 0.0 & 40.1 & 50.1 & 7.2 & 20.3 & 14.6 & 22.5 & 25.2 & 40.5 & 8.2 & 4.8 & 11.2 & \\
\hline $\boldsymbol{B}$ & 0.0 & 0.0 & 11.4 & 25.7 & 41.0 & 18.3 & 52.9 & 33.9 & 41.5 & 7.9 & 7.0 & 11.6 & \\
\hline $\boldsymbol{B}$ & 0.0 & 0.0 & 0.0 & 81.2 & 0.0 & 0.0 & 38.7 & 51.5 & 65.2 & 19.8 & 19.0 & 16.5 & \\
\hline $\boldsymbol{B}$ & 0.0 & 0.0 & 0.0 & 0.0 & 0.0 & 0.0 & 0.0 & 52.4 & 75.1 & 25.2 & 24.6 & 22.7 & \\
\hline $\boldsymbol{B}$ & 0.0 & 0.0 & 0.0 & 0.0 & 0.0 & 0.0 & 0.0 & 56.6 & 84.6 & 25.2 & 24.6 & 22.7 & \\
\hline $\boldsymbol{B}$ & 0.0 & 0.0 & 0.0 & 0.0 & 0.0 & 0.0 & 0.0 & 80.3 & 139.3 & 30.3 & 29.5 & 22.7 & \\
\hline$B$ & 0.0 & 0.0 & 0.0 & 0.0 & 0.0 & 0.0 & 0.0 & 132.1 & 96.4 & 118.0 & 137.9 & 103.8 & \\
\hline \multicolumn{14}{|c|}{$B^{\prime}$ values } \\
\hline$B^{\prime}$ & 30.2 & 21.8 & 13.7 & 3.9 & 7.8 & 3.3 & 0.0 & 26.8 & 49.5 & 0.0 & 22.2 & 11.3 & \\
\hline $\boldsymbol{B}^{\prime}$ & 30.2 & 2.9 & 38.4 & 29.5 & 0.0 & 40.2 & 10.0 & 10.4 & 20.3 & 0.0 & 22.2 & 11.3 & \\
\hline$B^{\prime}$ & 60.0 & 61.4 & 38.4 & 6.6 & 72.0 & 0.0 & 16.8 & 16.7 & 25.6 & 0.0 & 22.2 & 11.3 & \\
\hline $\boldsymbol{B}^{\prime}$ & 0.0 & 40.0 & 50.0 & 21.1 & 24.8 & 14.7 & 34.9 & 26.6 & 49.4 & 2.2 & 12.0 & 11.1 & \\
\hline$B^{\prime}$ & 0.0 & 0.0 & 13.7 & 48.1 & 40.1 & 24.2 & 50.2 & 47.1 & 49.5 & 10.8 & 23.1 & 11.3 & \\
\hline$B^{\prime}$ & 0.0 & 0.0 & 0.0 & 61.6 & 0.0 & 0.0 & 16.6 & 110.5 & 86.8 & 25.3 & 23.1 & 13.0 & \\
\hline$B^{\prime}$ & 0.0 & 0.0 & 0.0 & 0.0 & 0.0 & 0.0 & 0.0 & 24.9 & 33.2 & 26.7 & 24.6 & 15.5 & \\
\hline $\boldsymbol{B}^{\prime}$ & 0.0 & 0.0 & 0.0 & 0.0 & 0.0 & 0.0 & 0.0 & 33.3 & 48.8 & 26.7 & 24.6 & 15.5 & \\
\hline $\boldsymbol{B}^{\prime}$ & 0.0 & 0.0 & 0.0 & 0.0 & 0.0 & 0.0 & 0.0 & 64.2 & 102.7 & 16.4 & 13.8 & 15.5 & \\
\hline$B^{\prime}$ & 0.0 & 0.0 & 0.0 & 0.0 & 0.0 & 0.0 & 0.0 & 102.5 & 63.9 & 73.8 & 102.7 & 100.9 & \\
\hline \multicolumn{14}{|l|}{ Indexes } \\
\hline$B / 100$ & 1.2 & 1.2 & 1.4 & 1.6 & 1.3 & 0.9 & 1.5 & 4.9 & 6.3 & 2.3 & 2.9 & 2.5 & \\
\hline$B^{\prime} / 100$ & 1.2 & 1.3 & 1.5 & 1.7 & 1.4 & 0.8 & 1.3 & 4.6 & 5.3 & 1.8 & 2.9 & 2.2 & \\
\hline$m / v / 10$ & 1.5 & 0.9 & 0.6 & 0.8 & 0.9 & 1.7 & 1.0 & 0.3 & 0.2 & 0.9 & 0.6 & 0.2 & \\
\hline$D$ & 0.8 & 1.1 & 1.3 & 1.4 & 1.0 & 0.9 & 1.0 & 2.1 & 1.9 & 1.7 & 2.5 & 3.8 & \\
\hline $\boldsymbol{\lambda}$ & 0.6 & 0.7 & 0.8 & 0.7 & 0.7 & 0.5 & 0.7 & 0.9 & 0.9 & 0.5 & 0.6 & 0.9 & \\
\hline $\boldsymbol{H}$ & 1.0 & 1.6 & 1.9 & 1.8 & 1.6 & 1.2 & 1.7 & 3.5 & 3.4 & 3.6 & 3.7 & 2.3 & \\
\hline $\boldsymbol{H}^{\prime}$ & 3.5 & 4.1 & 4.5 & 5.3 & 4.3 & 4.9 & 5.6 & 3.0 & 3.2 & 5.1 & 2.1 & 3.3 & \\
\hline$J^{\prime}$ & 0.0 & 0.2 & 0.4 & 0.4 & 0.2 & 0.1 & 0.4 & 1.6 & 1.6 & 1.2 & 1.7 & 1.1 & \\
\hline
\end{tabular}




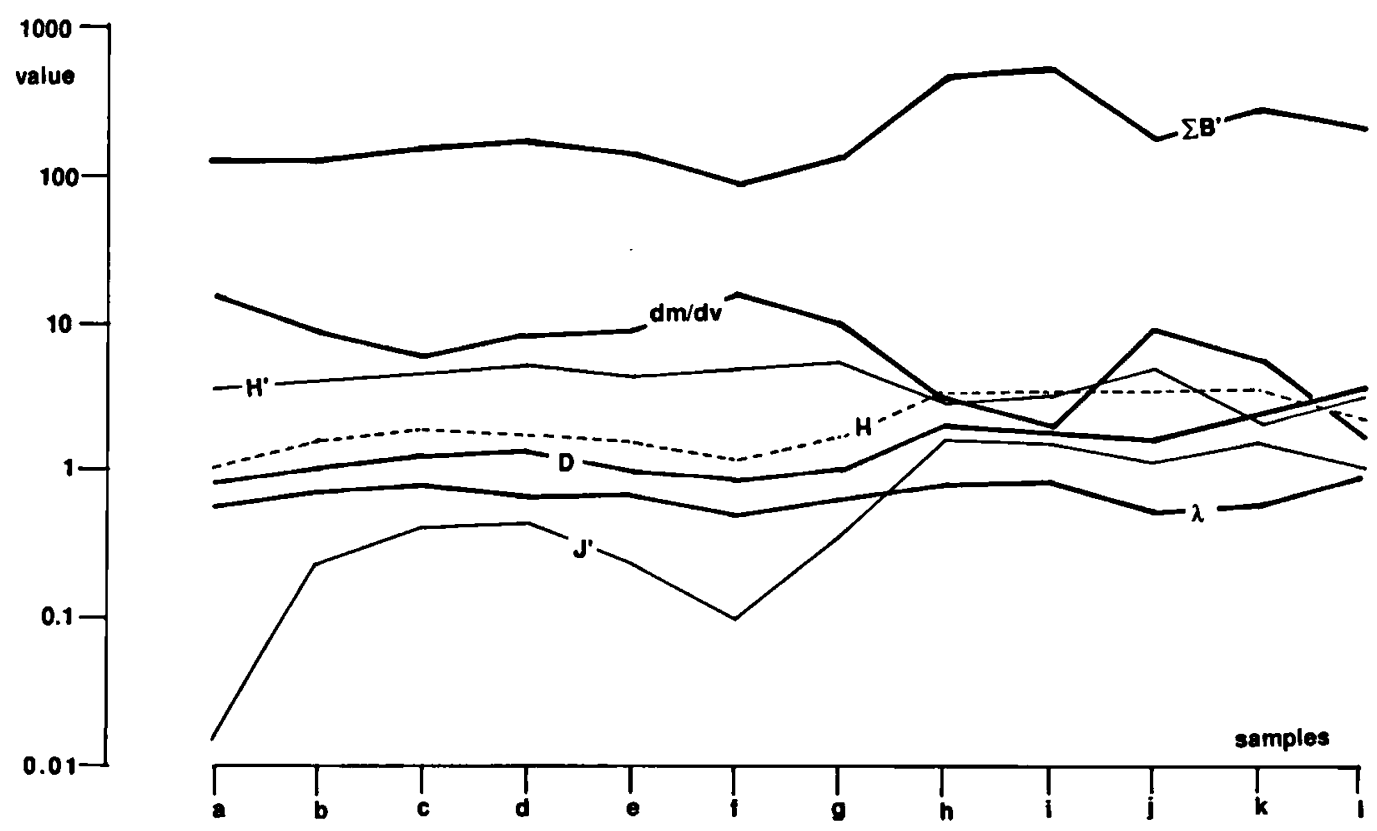

Fig. 9. The different values of diversity indexes for 10 species in 12 samples (cf. Table I).

Here $\% N \max$ is the percentage of the most abundant species and $S$ is the number of species, each of which forms more than e.g., $2 \%$ of the sample (for an example see Table I: line $m / v / 10$ ).

The diversity index proposed by Margalef (1951) is expressed as:

$$
D=(S-1) / \ln N
$$

Here $S$ is the number of species and $N$ the total number of individuals in the sample (for an example see Table I: line $D$ ).

Simpson's (1949) index also compares whole samples and is expressed as a probability:

$$
\lambda=\sum_{i=1}^{S}\left(n_{i} / N\right)^{2}
$$

Here $S$ is the total number of species, $N$ the total number of the specimens, and $n_{i}$ the number of specimens of each single species (for an example see Table I: line $\lambda$ ).

Margalef $(1957,1958)$ developed the information index for diversity:

$$
H=3.321928 / N \times\left(\log N !-\sum_{i=1}^{S} \log n_{i} !\right)
$$

or

$$
H^{\prime}=3.321928 / N \times\left(N \times \log N-\sum_{i=1}^{S} n_{i} \times \log n_{i}\right)
$$

Here $N$ is the total number of specimens and $n_{i}$ are the respective numbers of specimens of each species. In the formula for $\boldsymbol{H}^{\prime}$, directly observed values are used, which is allowed with large values for $N$ and $n$ (for an example see Table I: line $H$ and $\boldsymbol{H}^{\prime}$ ).

Pielou (1966) proposed as an evenness component the diversity index:

$$
J^{\prime}=H^{\prime}: \log _{2} S
$$

Here $H^{\prime}$ of Margalef's equation is used and $S$ represents the number of species (for an example see Table I: line $J^{\prime}$ ).

Omori \& Ikeda (1984) gave a nice overview of the 
use of these and a few other calculations for plankton diversity.

In Fig. 9 and Table I the different indexes given above are illustrated for a hypothetical collection of 10 species and 12 samples. The number of specimens per species for this collection is given in Fig. 10 together with the $B$ and $B^{\prime}$ values for the individual species. In the upper left sample or fauna of Fig. 10 (sample 1), nine of the ten species are represented by the same numbers of specimens. Still the five species most to the upper right in Fig. 10 contribute more to diversity in that fauna than the five species to the lower left, as the five species to the right are absent in the seven first samples or faunas at the right of Fig. 10.

It might seem not very useful for the diversity calculations with $B$ and even with $B^{\prime}$ that the number of individuals has a large influence on the outcome. This is, however, not corrected for further, as the within-species diversity discussed below becomes greater as the numbers of specimens are greater. So $B$ as well as $B^{\prime}$ may be considered also to represent, though primitively, the genetic variability.

The fact that in $B^{\prime}$ and especially in $B$ the diversity value which is calculated for each species depends also on the presence of that species in other samples makes this kind of index more a value for the contribution to diversity as shown in Table II and Fig. 11. The greater the $B$ value of a species, the greater is the effect of its disappearance. In Fig. 11, widespread species, endemic species, and disjunct species are considered; the more restricted the distribution of a species is, the more it contributes to diversity (when present) as shown by Figs. 10 and 11. Especially $B$ but also $B^{\prime}$ show this (see Table II).

For the numerical approach, not only adequate sampling is required but also a good taxonomic knowledge of the group investigated is needed. The diversity described in Diacavolinia by Van der Spoel et al. (1993) is a good example for demonstrating this problem. One widespread species: Cavolinia longirostris (De Blainville, 1821) was split into 24 species more restricted in distribution. Calculations based on the old concept of this pteropod group give diversity indexes that are too low when larger areas are considered. When small areas are considered, no influence is found as most species newly described are usually allopatric.

When newly described species are sympatric, they add to the diversity also when small areas are considered. The safest way to calculate diversity is to investigate well-known groups in small geographic areas and to use large numbers of species in the comparisons. Especially the $D m / D v$ and $H^{\prime}$ indexes change when a species is split into sympatric new species. The $B$ and especially the $B^{\prime}$ indexes are influenced when allopatric new species occur, as these values also depend on other studied samples or faunas (see Table III).

Genetic diversity - So far numerical diversity has been considered. A fauna of " $A$ " species each with " $B$ " homozygotic specimens is evidently less diverse than a fauna with " $A$ " species each with "B" heterozygotic specimens. Thus genetics, though not strictly belonging to biosystematics, has to be considered.

The genetic and phylogenetic diversity will have much to do with the diversity in the future as they try to describe the potential present in the biota with regard to diversity, thus the ability to duplicate existing diversity or to generate new diversity. Only a few studies are made about the genetics of plankton and nekton. Available data, however, prove that within one species different populations with different gene pools can be found. Crosses of Acartia clausi Giesbrecht, 1889 from the Pacific with Atlantic specimens are unproductive (Carillo et al., 1974). Genetic differences between geographically more close populations of several species are discussed by Buchlin (1986). Though it is difficult to distinguish between populations in the ocean, recent research proved that there is much more diversity at the population level in the oceanic realm than was expected in the past.

The variation of genetic characters within a population (genetic polymorphism) seems of minor importance for diversity, as one may suppose that this variability will generate equally in all populations. The differences described by Carillo et al. (1974) (genetic polytypism) seem of more importance and so is the variation found in clines, e.g., 

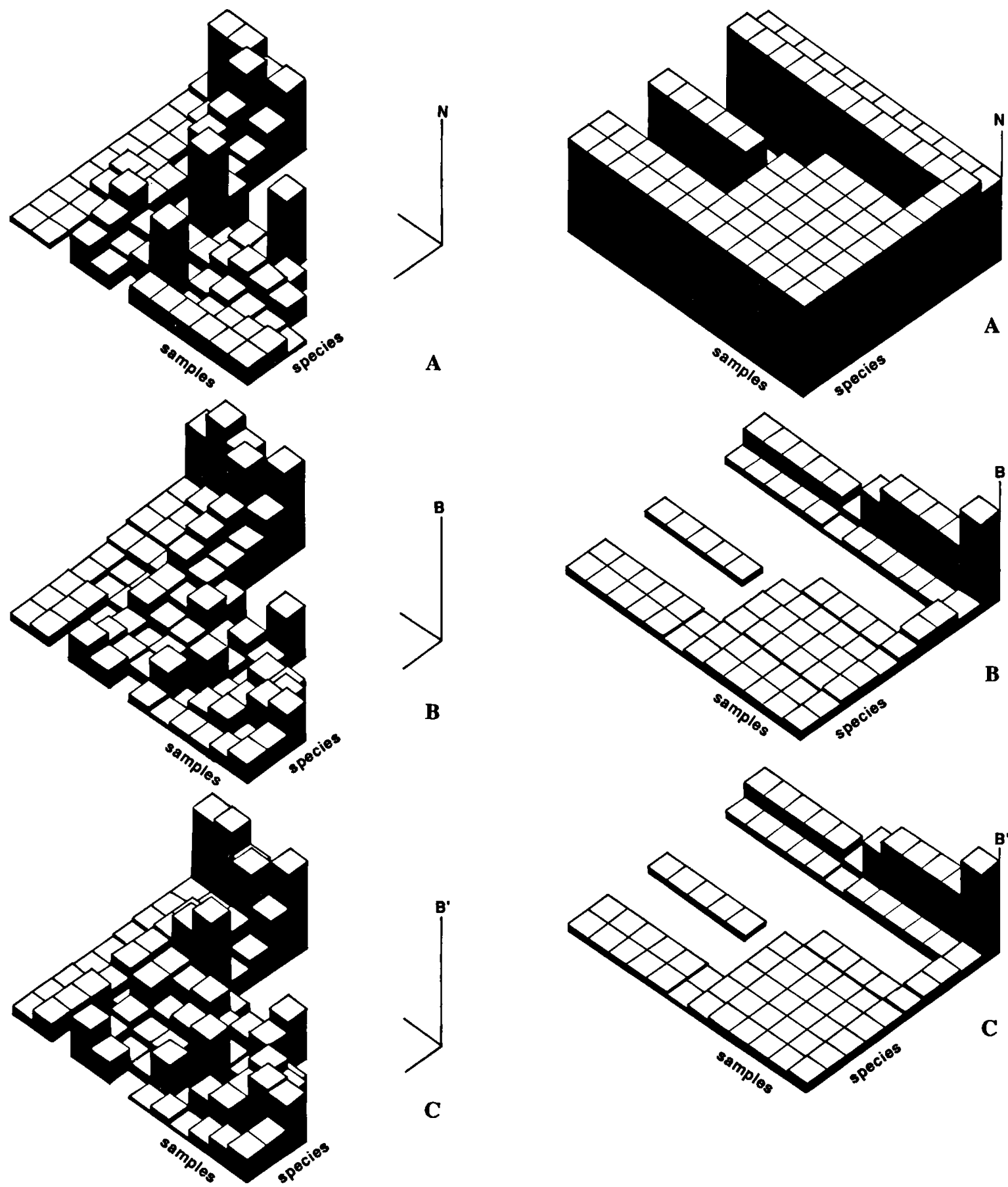

A
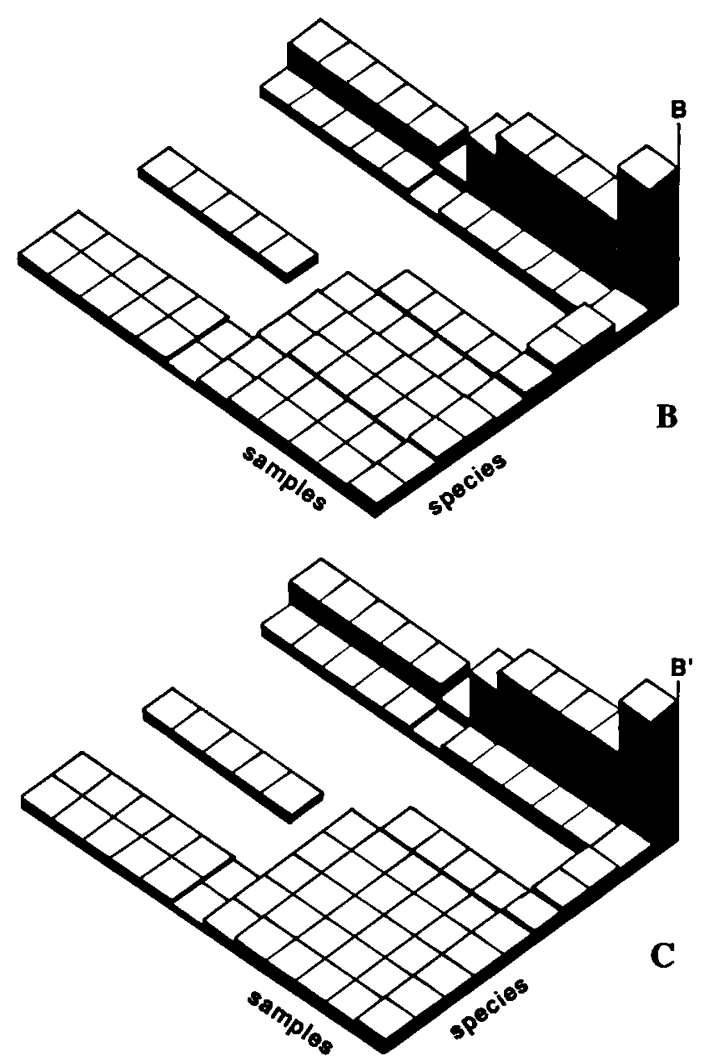

C

Fig. 10. Ten species (y-axis) in twelve samples (x-axis) represented by their total numbers (z-axis) in $A$, by their $B^{\prime}$ values in $C$, and by their $B$ values (z-axis) in $B$. These samples form also the basis for the values given in Fig. 9.

Fig. 11. Diagrams for wide and narrowly distributed species using the data in Table II. In $A$ the number of specimens per species and sample $(N)$ are given, in $B$ the value $B$, and in $C$ the value $B^{\prime}$ is given in the same way. Notice the large contribution to diversity by species that are absent from other samples. 
Table II. Data set for widely and less widely distributed species.

\begin{tabular}{|c|c|c|c|c|c|c|c|c|c|c|c|c|}
\hline species & a & b & c & d & e & f & $\mathbf{g}$ & $\mathbf{h}$ & $\mathbf{i}$ & $\mathbf{j}$ & $\mathbf{k}$ & 1 samples \\
\hline \multicolumn{13}{|l|}{ Data } \\
\hline I & 8 & 8 & 8 & 8 & 8 & 8 & 8 & 8 & 8 & 8 & 8 & 8 \\
\hline II & 8 & 8 & 8 & 8 & 8 & 8 & 8 & 8 & 8 & 8 & 8 & 8 \\
\hline III & 8 & 8 & 8 & 8 & 8 & 8 & 0 & 0 & 0 & 0 & 0 & 0 \\
\hline IV & 8 & 8 & 8 & 8 & 8 & 8 & 0 & 0 & 0 & 0 & 0 & 0 \\
\hline $\mathbf{V}$ & 8 & 8 & 8 & 8 & 8 & 8 & 0 & 8 & 8 & 8 & 8 & 8 \\
\hline VI & 8 & 8 & 8 & 8 & 8 & 0 & 0 & 0 & 0 & 0 & $\mathbf{0}$ & 0 \\
\hline VII & 8 & 0 & 0 & 0 & 0 & 0 & 0 & 0 & 0 & 0 & 0 & 0 \\
\hline VIII & 8 & 0 & 0 & 0 & 0 & 0 & 0 & 0 & 0 & 0 & 0 & 0 \\
\hline IX & 8 & 8 & 8 & 8 & 8 & 8 & 8 & 8 & 8 & 8 & 8 & 8 \\
\hline $\mathbf{x}$ & 7 & 7 & 7 & 7 & 7 & 7 & 7 & 7 & 7 & 7 & 7 & 7 \\
\hline \multicolumn{13}{|l|}{$B$ values } \\
\hline$B$ & 100.0 & 80.0 & 80.0 & 80.0 & 80.0 & 70.1 & 40.1 & 50.1 & 50.1 & 50.1 & 50.1 & 50.1 \\
\hline$B$ & 100.0 & 80.0 & 80.0 & 80.0 & 80.0 & 70.1 & 40.1 & 50.1 & 50.1 & 50.1 & 50.1 & 50.1 \\
\hline $\boldsymbol{B}$ & 112.9 & 95.6 & 95.6 & 95.6 & 95.6 & 87.4 & 0.0 & 0.0 & 0.0 & 0.0 & 0.0 & 0.0 \\
\hline$B$ & 112.9 & 95.6 & 95.6 & 95.6 & 95.6 & 87.4 & 0.0 & 0.0 & 0.0 & 0.0 & 0.0 & 0.0 \\
\hline $\boldsymbol{B}$ & 100.3 & 80.4 & 80.4 & 80.4 & 80.4 & 70.5 & 0.0 & 50.6 & 50.6 & 50.6 & 50.6 & 50.6 \\
\hline $\boldsymbol{B}$ & 118.7 & 102.4 & 102.4 & 102.4 & 102.4 & 0.0 & 0.0 & 0.0 & 0.0 & 0.0 & 0.0 & 0.0 \\
\hline $\boldsymbol{B}$ & 154.4 & 0.0 & 0.0 & 0.0 & 0.0 & 0.0 & 0.0 & 0.0 & 0.0 & 0.0 & 0.0 & 0.0 \\
\hline$B$ & 154.4 & 0.0 & 0.0 & 0.0 & 0.0 & 0.0 & 0.0 & 0.0 & 0.0 & 0.0 & 0.0 & 0.0 \\
\hline $\boldsymbol{B}$ & 100.0 & 80.0 & 80.0 & 80.0 & 80.0 & 70.1 & 40.1 & 50.1 & 50.1 & 50.1 & 50.1 & 50.1 \\
\hline$B$ & 900.0 & 560.0 & 560.0 & 560.0 & 560.0 & 420.0 & 120.0 & 200.0 & 200.0 & 200.0 & 200.0 & 200.0 \\
\hline \multicolumn{13}{|c|}{$B^{\prime}$ values } \\
\hline$B^{\prime}$ & 100.0 & 80.0 & 80.0 & 80.0 & 80.0 & 70.0 & 40.0 & 50.0 & 50.0 & 50.0 & 50.0 & 50.0 \\
\hline$B^{\prime}$ & 100.0 & 80.0 & 80.0 & 80.0 & 80.0 & 70.0 & 40.0 & 50.0 & 50.0 & 50.0 & 50.0 & 50.0 \\
\hline $\boldsymbol{B}^{\prime}$ & 101.6 & 82.0 & 82.0 & 82.0 & 82.0 & 72.3 & 0.0 & 0.0 & 0.0 & 0.0 & 0.0 & 0.0 \\
\hline$B^{\prime}$ & 101.6 & 82.0 & 82.0 & 82.0 & 82.0 & 72.3 & 0.0 & 0.0 & 0.0 & 0.0 & 0.0 & 0.0 \\
\hline$B^{\prime}$ & 100.0 & 80.0 & 80.0 & 80.0 & 80.0 & 70.1 & 0.0 & 50.1 & 50.1 & 50.1 & 50.1 & 50.1 \\
\hline $\boldsymbol{B}^{\prime}$ & 102.4 & 83.0 & 83.0 & 83.0 & 83.0 & 0.0 & 0.0 & 0.0 & 0.0 & 0.0 & 0.0 & 0.0 \\
\hline$B^{\prime}$ & 107.9 & 0.0 & 0.0 & 0.0 & 0.0 & 0.0 & 0.0 & 0.0 & 0.0 & 0.0 & 0.0 & 0.0 \\
\hline $\boldsymbol{B}^{\prime}$ & 107.9 & 0.0 & 0.0 & 0.0 & 0.0 & 0.0 & 0.0 & 0.0 & 0.0 & 0.0 & 0.0 & 0.0 \\
\hline $\boldsymbol{B}^{\prime}$ & 100.0 & 80.0 & 80.0 & 80.0 & 80.0 & 70.0 & 40.0 & 50.0 & 50.0 & 50.0 & 50.0 & 50.0 \\
\hline$B^{\prime}$ & 900.0 & 560.0 & 560.0 & 560.0 & 560.0 & 420.0 & 120.0 & 200.0 & 200.0 & 200.0 & 200.0 & 200.0 \\
\hline \multicolumn{13}{|l|}{ Indexes } \\
\hline$B / 100$ & 19.5 & 19.5 & 19.5 & 19.5 & 19.5 & 19.5 & 19.5 & 19.5 & 19.5 & 19.5 & 19.5 & 19.5 \\
\hline$B^{\prime} / 100$ & 18.2 & 18.2 & 18.2 & 18.2 & 18.2 & 18.2 & 18.2 & 18.2 & 18.2 & 18.2 & 18.2 & 18.2 \\
\hline$m / v / 10$ & 0.1 & 0.1 & 0.1 & 0.1 & 0.1 & 0.1 & 0.1 & 0.1 & 0.1 & 0.1 & 0.1 & 0.1 \\
\hline$D$ & 2.1 & 1.7 & 1.7 & 1.7 & 1.7 & 1.5 & 0.9 & 1.1 & 1.1 & 1.1 & 1.1 & 1.1 \\
\hline$\lambda$ & 0.9 & 0.9 & 0.9 & 0.9 & 0.9 & 0.9 & 0.7 & 0.8 & 0.8 & 0.8 & 0.8 & 0.8 \\
\hline $\boldsymbol{H}$ & 3.2 & 2.9 & 2.9 & 2.9 & 2.9 & 2.7 & 2.2 & 2.4 & 2.4 & 2.4 & 2.4 & 2.4 \\
\hline $\boldsymbol{H}^{\prime}$ & 3.3 & 3.0 & 3.0 & 3.0 & 3.0 & 2.8 & 2.0 & 2.3 & 2.3 & 2.3 & 2.3 & 2.3 \\
\hline$J^{\prime}$ & 1.5 & 1.1 & 1.1 & 1.1 & 1.1 & 0.9 & 0.4 & 0.6 & 0.6 & 0.6 & 0.6 & 0.6 \\
\hline
\end{tabular}

as described by Van der Spoel (1967) for Clio pyramidata.

When subspecies or semispecies as described for Acartia clausi are added to (or subtracted from) an area, the gene pool changes with a resultant change in diversity. The same may hold true if forms in a cline are concerned. The diversity in the northern Pacific Ocean is different from that in the northern Atlantic Ocean, among other factors, by the fact that the cold-water form of Clio pyramidata is ab- 
Table III. Data set for a fauna with a single species VII not split and species VII split up into 4 "new" species.

\begin{tabular}{|c|c|c|c|c|c|c|c|c|c|c|c|c|}
\hline species & a & $\mathbf{b}$ & c & d & e & f & g & h & $\mathbf{i}$ & $\mathbf{j}$ & $\mathbf{k}$ & 1 sample \\
\hline \multicolumn{13}{|c|}{ Data with taxon VII composed of 4 species } \\
\hline I & 5 & 3 & 6 & 15 & 16 & 16 & 1 & 3 & 6 & 7 & 6 & 10 \\
\hline II & 1 & 5 & 6 & 6 & 7 & 12 & 2 & 8 & 8 & 16 & 5 & 8 \\
\hline III & 2 & 2 & 3 & 2 & 19 & 4 & 21 & 6 & 9 & 4 & 6 & 8 \\
\hline IV & 6 & 1 & 9 & 19 & 5 & 6 & 5 & 12 & 13 & 5 & 6 & 8 \\
\hline V & 5 & 4 & 14 & 12 & 4 & 7 & 16 & 5 & 15 & 5 & 13 & 8 \\
\hline VI & 4 & 5 & 5 & 15 & 5 & 18 & 17 & 14 & 1 & 15 & 5 & 8 \\
\hline VII & 8 & 10 & 0 & 0 & 0 & 13 & 2 & 0 & 10 & 0 & 0 & 0 \\
\hline VIIa & 0 & 0 & 21 & 7 & 6 & 0 & 2 & 0 & 0 & 18 & 0 & 0 \\
\hline VIIb & 0 & 0 & 0 & 0 & 4 & 8 & 6 & 10 & 0 & 0 & 16 & 0 \\
\hline VIIc & 0 & 0 & 0 & 0 & 0 & 0 & 2 & 16 & 0 & 0 & 0 & 8 \\
\hline \multicolumn{13}{|c|}{ Data with taxon VII composed of 1 species } \\
\hline I & 5 & 3 & 6 & 15 & 16 & 16 & 1 & 3 & 6 & 7 & 6 & 10 \\
\hline II & 1 & 5 & 6 & 6 & 7 & 12 & 2 & 8 & 8 & 16 & 5 & 8 \\
\hline III & 2 & 2 & 3 & 2 & 19 & 4 & 21 & 6 & 9 & 4 & 6 & 8 \\
\hline IV & 6 & 1 & 9 & 19 & 5 & 6 & 5 & 12 & 13 & 5 & 6 & 8 \\
\hline $\mathbf{V}$ & 5 & 4 & 14 & 12 & 4 & 7 & 16 & 5 & 15 & 5 & 13 & 8 \\
\hline VI & 4 & 5 & 5 & 15 & 5 & 18 & 17 & 14 & 1 & 15 & 5 & 8 \\
\hline VII & 8 & 10 & 21 & 7 & 10 & 21 & 12 & 16 & 10 & 18 & 16 & 8 \\
\hline \multicolumn{13}{|c|}{ Difference in the values found for the indexes based on the two data sets above } \\
\hline$B / 100$ & 0.8 & 0.4 & 0.3 & 0.9 & 0.1 & -0.4 & -1.0 & 0.0 & 0.5 & 0.9 & 0.5 & -0.2 \\
\hline$B^{\prime} / 100$ & 1.3 & 1.0 & 1.0 & 1.5 & 1.0 & 0.7 & 0.1 & 0.8 & 1.5 & 1.5 & 1.0 & 0.4 \\
\hline$m / v / 10$ & 0.0 & 0.0 & 0.0 & 0.0 & 0.5 & 0.9 & 1.2 & 0.8 & 0.0 & 0.0 & 0.0 & 0.0 \\
\hline$D$ & 0.0 & 0.0 & 0.0 & 0.0 & -0.2 & -0.2 & -0.7 & -0.2 & 0.0 & 0.0 & 0.0 & 0.0 \\
\hline$\lambda$ & 0.0 & 0.0 & 0.0 & 0.0 & 0.0 & 0.0 & 0.0 & 0.0 & 0.0 & 0.0 & 0.0 & 0.0 \\
\hline $\boldsymbol{H}$ & 0.0 & 0.0 & 0.0 & 0.0 & -0.1 & -0.2 & -0.2 & -0.4 & 0.0 & 0.0 & 0.0 & -0.3 \\
\hline$H^{\prime}$ & 0.3 & 0.3 & -1.0 & 0.1 & 1.1 & 0.4 & 3.4 & -0.4 & 0.2 & 0.2 & 0.4 & 1.2 \\
\hline$J^{\prime}$ & 0.0 & 0.0 & 0.0 & 0.0 & -0.2 & -0.2 & -0.4 & -0.3 & 0.0 & 0.0 & 0.0 & -0.1 \\
\hline
\end{tabular}

sent in the first and present in the latter area (Van der Spoel \& Heyman, 1983). Subspecies and forms, moreover, may be considered as the first steps in the speciation process, so that they will contribute to future diversity.

For a full detection of diversity, it is thus important to incorporate subspecific taxa in the calculations. For the detection of present-day diversity, it may suffice to determine the higher taxa diversity and species diversity based on the morphological species concept. The subspecific diversity based on a genetic species concept should be incorporated in the calculations when a long-term diversity is calculated. Biochemical methods to distinguish between geographically separated pelagic populations and to investigate their geographic extensions will be an important tool in the future.
Phylogenetic diversity - The diversity expressed in phylogenetic relationships is slightly different from the genetic diversity. This is because the genetic variability which forms the basis of genetic diversity may concern all types of genetic characters, while phylogenetic diversity looks for characters, variable or not, that are developed at a certain moment in evolution. In the cladogram in Fig. 4, the species " $L$ " may still have character states that are lost in the species " $A$ " to " $K$ ". The ability of species " $L$ " to generate other species with these special character states makes it of more importance for diversity than those species lacking that possibility.

However, recently developed characters also have their special value. Comparing the areas 1 to 7 (Fig. 4) in which the species " $A$ " to " $L$ " are found, say in equal numbers, may give rise to seem- 
Table IV. Phylogenetic diversity calculation for the species A to E, modified after Vane-Wright et al. (1991). $G=$ the number of higher "species"-groups to which a species belongs; $W=(\Sigma G / G) /\left(\Sigma G / G_{\mathrm{for} \mathrm{species} \mathrm{A}}\right) ; R=$ regions of occurrence indicated with 1 and regions of absence indicated with 0 . For further explanation, cf. Fig. 12 and text.

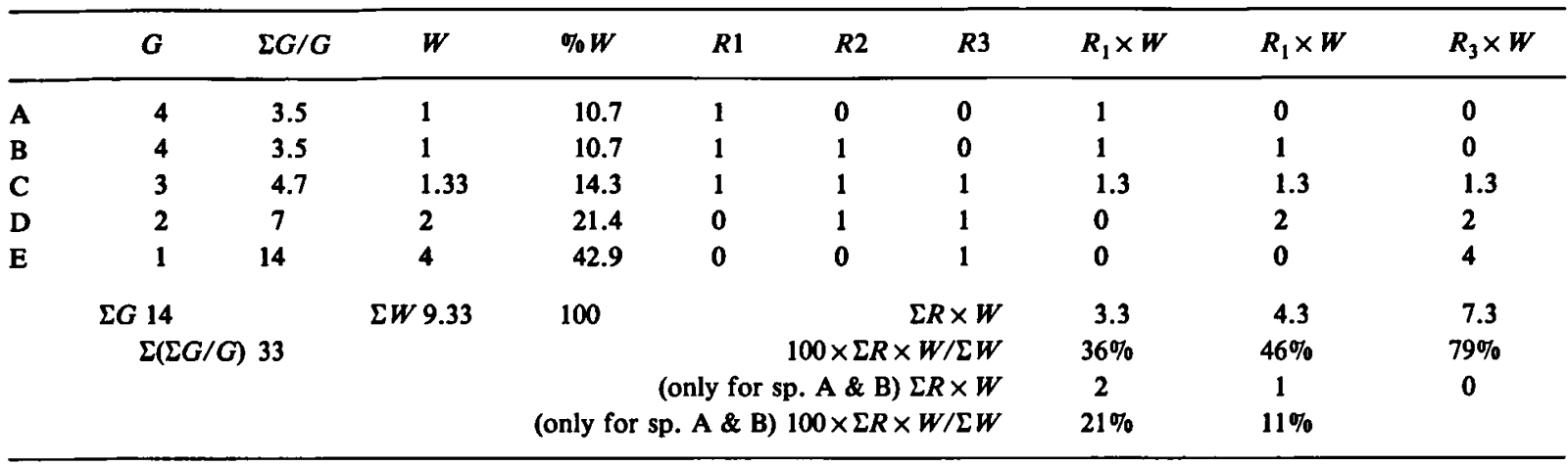
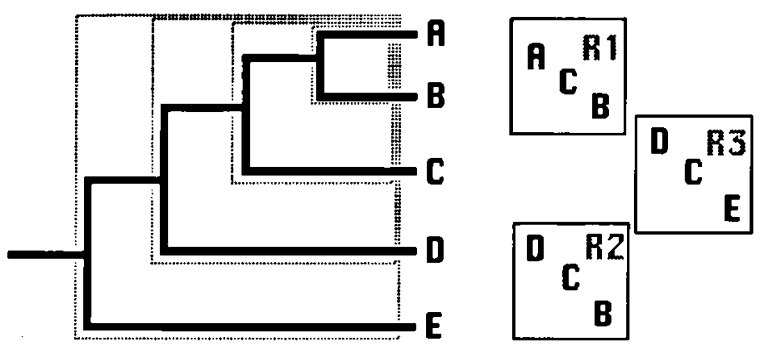

Fig. 12. Hypothetical cladogram for five species (A-E) with their distribution areas (R1-R3) (after Vane-Wright et al., 1991).

ingly contradictory conclusions. Area 6 is the most diverse area and area 5 has the lowest diversity, numerically as well as phylogenetically. Also, area 1 and 2 are of a same numerical diversity, but in area 1 only original taxa (with plesiomorphic characters) are found, while in area 2 original and derived taxa (with apomorphic characters) are found; for this reason area 2 can be considered the most diverse of the two. The areas 3 and 4 are also of the same numerical diversity, but area 3 shows much less phylogenetic distance between the taxa than area 4 , so that area 4 is more diverse.

For environmental studies, this application of phylogeny to select between more and less valuable areas, in terms of natural preservation, is proposed by Vane-Wright et al. (1991). The contribution of the species to phylogenetic diversity is calculated by counting (see Table IV) the groups in a cladogram (given in Fig. 12) to which a species belongs $(G)$ and dividing that by the sum $(\Sigma G)$ of these values. For convenience this figure in the second column is divided by the value of the first species and shown as $W^{\prime}$ or as $W$ in percentages. So the contribution of a species to diversity can be given as:

$$
\begin{gathered}
D_{\text {phylogenetic }}=(\Sigma G / G) /\left(\Sigma G / G_{\text {of first species }}\right)= \\
G_{\text {of first species }} / G
\end{gathered}
$$

For a special area the diversity is then the sum of these values expressed as percentage of the total possible diversity $\Sigma W$ :

$$
D_{\text {phylogenetic }}=100 \times \Sigma\left(G_{\text {of first species }} / G\right) /(\Sigma W)
$$

In Fig. 12 the cladogram for the species in Table IV is given. The areas R1 to R3 are used in that figure to demonstrate how the phylogenetic contribution to diversity for an area can be calculated. For a full discussion of this method, one is referred to VaneWright et al. (1991); here it suffices to show that area R3 with $79 \%$ of the phylogenetic diversity is the most important one to preserve. The species $\mathbf{A}$ and $B$ then would not be saved or preserved so that for the second choice only A and B has to be considered. This gives area $R 1$ with $21 \%$ as the most important area to preserve. In the selection "Diversity formulated", the application of this method is discussed in relation to the other diversity calculations.

Historical diversity - Areas of origin and centres of dispersal are concepts related to dispersal biogeog- 
raphy, the "ad hoc" discipline as it was called by Humpries \& Parenti (1986). Though this is completely true, one cannot work in pelagic biogeography without using this "ad hoc" discipline. Currents constantly disperse taxa and whole biota. In some regions, currents transport whole faunas through special areas.

Brackish-water areas are very disjunct and their existence is of short duration. Neritic waters are likewise disjunct and unstable, and of geologically short duration. Tokioka (1979) proposed considering neritic faunas as derived from oceanic communities by migration, thus dispersal, of taxa of the ocean into the neritic areas, where they start to speciate.

For open ocean taxa, Beklemishev (1971) distinguished (1) primary communities and ecosystems in gyral water masses and (2) derived secondary ones in terminal waters. This theory is based on the assumption that populations in gyral waters can persist, as the specimens constituting the population circulate through the water (either horizontally or vertically) and thus tend to return always to the same places, while specimens of populations in terminal waters drift away with the currents and become lost for the ecosystem. In terminal waters, in the long run, all specimens will disappear and new ones, originating from the gyral systems, have to replace the lost ones.

In parallel, species of gyral systems seem to be ancestral to terminal water species (Van der Spoel \& Heyman, 1983; Van der Spoel et al., 1990). For the pelagic area it is thus possible to consider Central waters as areas of origin, and terminal waters and neritic waters as having derived faunas.

Even when vicariance biogeography can be applied in the pelagic realm, the distribution patterns and diversity distribution cannot be explained without using dispersal principles (Van der Spoel et al., 1990).

Summarizing this in a formula, the historical diversity ( $D$ historical) can be expressed as

$$
\begin{gathered}
D_{\text {historical }}=N \text { spec. } \times\left(N_{\text {primary sp. }} / N_{\text {secondary sp. }}\right) \times \\
\left(N_{\text {oceanic sp. }} / N_{\text {neritic sp. }}\right) / \text { area size }
\end{gathered}
$$

Here Nspec. represents the numerical diversity that can also be expressed by one of the calculated values given in the section "Diversity calculation". The ratio of derived and non-derived taxa then changes the value of diversity relative to the area studied.

Ecological diversity - Diversity is a functional concept. In an area with ten species belonging to the same community, there is less functional diversity than in an area with ten species belonging to two communities. Each community has its typical function in the world ecosystem. Thus if numerical, genetic, or phylogenetic diversity is considered to be very low, for any reason, ecological diversity can be still very high as the fauna under consideration may be composed of diverse communities. When for example a temperate coastal-sea area is investigated, it may prove to harbour a pelagic fauna of low species diversity, low genetic diversity, and low phylogenetic diversity. The estuarine inlet waters usually will show the lowest values. As shown above, their historical value is also small, so that for future diversity these areas are not so important. Can we thus neglect this estuarine diversity? Disappearance of one or a few of the estuarine species will immediately affect the energy and biomass flow through the ecosystem, and each change in the diversity will have a direct and hazardous impact. Biologically it may be true that the diversity value of inlet waters is low. However, for human society, that value of diversity is of great importance, as it affects directly part of our local environment, and especially a part providing us with many natural resources.

The remark by Lasserre (1992): "some marine ecosystems may appear much more adaptable than individual species" seems to decrease the importance of ecological diversity. Is it true that it is not the species but the (eco)system that has the greatest tolerance or adaptability? In my opinion, this statement is due to a confusion of historical and ecological diversity. Many ecosystems adapt to changing conditions by incorporating other species into the same system. But species show a kind of adaptability at a given moment in time. This determines the ecological diversity (the higher the number of flexible species, the greater is the ecological diversity), 
while the historical diversity determines the possibility of the ecosystem to adapt (the lower the historical diversity, the easier other or new species take the place of the present ones and the more adaptable is the ecosystem).

To determine the ecological diversity, one should calculate the number of communities or ecosystems in the fauna and the importance of these systems for the persistence of the fauna as a whole.

Summarizing this in a formula, the ecological diversity can be expressed as:

$$
\mathbf{D}_{\text {ecological }}=
$$

(Number of communities $\times$ Species ecological ability)

$$
\text { Environmental variability }
$$

The ecological ability can be expressed as the number of communities in which the species occurs plus the number of seasons that the species is present (because of species and community succession with the seasons). The environmental variability can be estimated as the number of niches available in the area.

For ecology, body size of a species is important as it reflects the biomass and energy potential of a species in an ecosystem. Body size of a group shows a non-linear distribution and some species for this reason may have a different impact on ecological diversity than others.

The ecological, or actual diversity and the historical, or long-term diversity are now clearly separated. A confusion between the two concepts is still possible, as "primary", "secondary", “oceanic" and "neritic", four ecological concepts, were used to define the historical diversity. However, these terms were used in the above formula to indicate the historical origin of these groups, as described by Beklemishev (1971) and Tokioka (1979). In the $D$ historical formula, these should not be considered as ecological terms.

Ecological diversity and other counts of diversity of an area are highly influenced by the succession phenomenon. In ecosystems and certainly in pelagic ecosystems of coastal and highly productive areas, the species composition changes with the season. It is therefore impossible to determine a diversity based on a one-season research. In all defini- tions and calculations, the "number of species" should better be changed into "the yearly number of species", if one wants to prevent misjudgements due to the extreme high diversity fluctuations in the $\mathrm{cm}-10 \mathrm{~km}$ and less than one year space-time scale (cf. Fig. 1).

\section{Diversity formulated}

From the above it is clear that diversity $(D)$ can be given many different values. For a given area we can state that the higher taxonomic categories give a particular diversity:

$$
D_{\text {higher-taxa }}=\left(N_{\mathrm{f}}+N_{\mathrm{o}}+N_{\mathrm{c}}\right) /\left(B_{\mathrm{s}}\right)
$$

For the species diversity the following calculation is proposed:

$$
\begin{gathered}
\Sigma B^{\prime}=\Sigma\left(\left(\left(1+A_{\max }-A\right)^{2} \times(1+M-A) \times N^{\prime}\right)+\right. \\
\left.\left(100 \times\left(F \times N^{\prime}-\Sigma N^{\prime}\right) /\left(F \times N_{\max }^{\prime}-\Sigma N^{\prime}\right) \times F / F_{\max }\right)^{2}\right)^{0.5}
\end{gathered}
$$

The genetic diversity ( $D_{\text {genetic }}$ ) can best be incorporated into $B^{\prime}$ by counting also the infraspecific taxa and genetically different populations when determining the $N^{\prime}$ values.

The phylogenetic diversity was defined as:

$$
D_{\text {phylogenetic }}=100 \times \Sigma\left(G_{\text {of first species }} / G\right) /(\Sigma W)
$$

the historical diversity as:

$$
\begin{aligned}
D_{\text {historical }}= & N \text { spec. } \times\left(N_{\text {primary sp. }} / N_{\text {secondary sp. }}\right) \times \\
& \left(N_{\text {oceanic sp. }} / N_{\text {neritic sp. }}\right) / \text { area size }
\end{aligned}
$$

and the ecological diversity as:

$$
\mathrm{D}_{\text {ecological }}=
$$

Number of communities $\times$ Ecological ability of species

Environmental variability

The total species diversity cannot be a mere sum of the five above-mentioned values as they are expressed in different units. It is possible, however, to replace the $N$ spec. in the formula for $D$ historical by $B$ or $B^{\prime}$. Moreover, multiplication with $D_{\text {ecological }}$ 


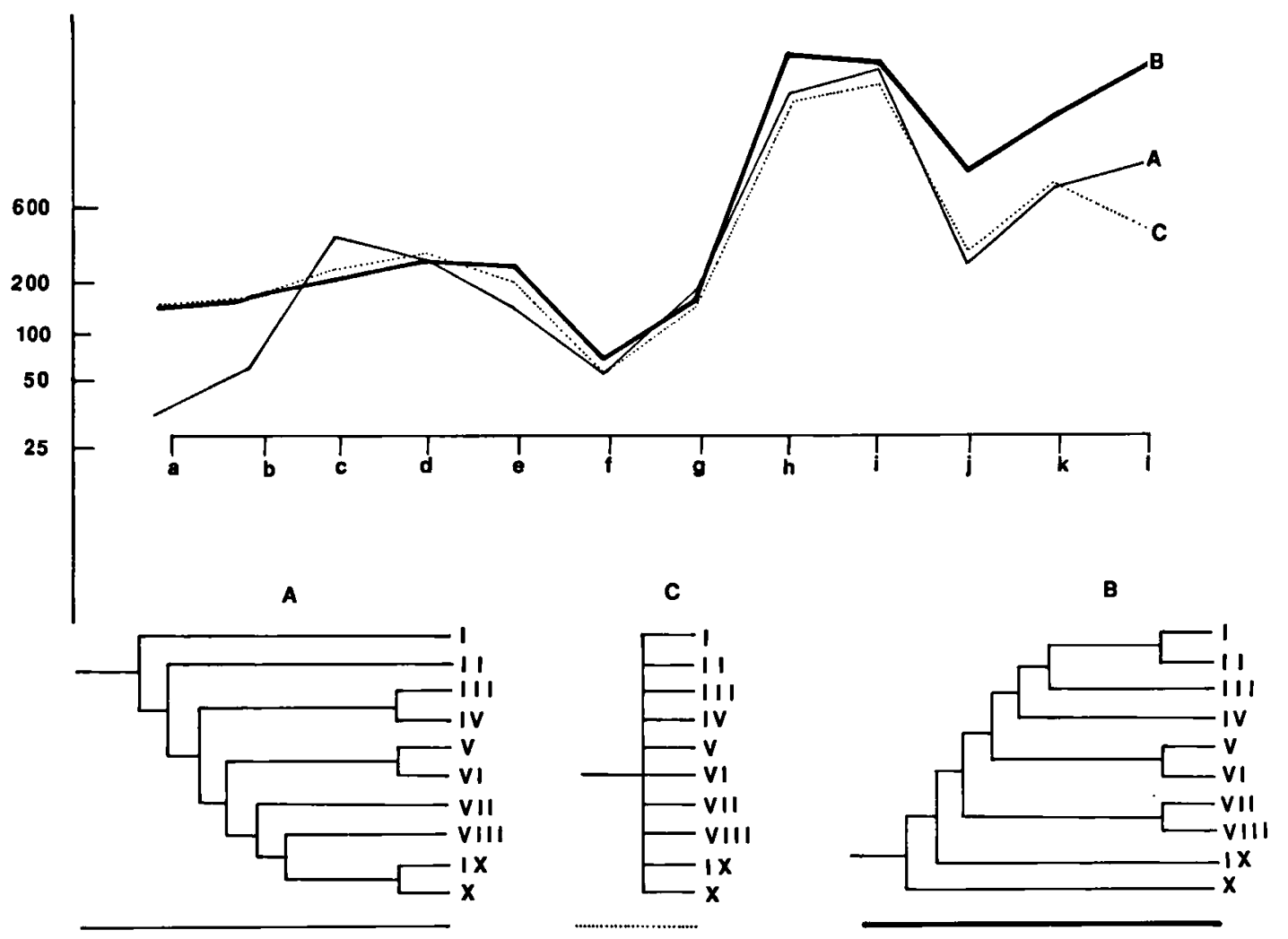

Fig. 13. Three different hypothetical cladograms for the ten species also used for the calculations in Table $I$ and the curves of the $B^{\prime}$ values: $\mathbf{A}$, when the phylogeny of cladogram $\mathbf{A}$ is applied; $\mathbf{B}$, when the cladogram $\mathbf{B}$ is applied; and $\mathbf{C}$, when phylogeny is not considered or when the cladogram $C$ is applied. The $W$ values for the species $I$ to $X$ are in cladogram $A$ respectively: $7,3.5,1.75,1.75,1.4,1.4$, $1.4,1.17,1$, and 1 ; for cladogram $B$ the sequence is reversed and for cladogram $C$ all values are 1.

is possible, as this formula deals in principle with the same level of species. Now we have a more general value for diversity:

$$
\begin{aligned}
& D_{\text {diversity }}=\left(B^{\prime} \times\left(N_{\text {primary sp. }} / N_{\text {secondary sp. }}\right) \times\right. \\
& \left.\left(N_{\text {oceanic sp. }} / N_{\text {neritic sp. }}\right) / \text { area size }\right) \times D_{\text {ecological }}
\end{aligned}
$$

or:

\footnotetext{
$D_{\text {diversity }}=\left(\left(\left(\left(1+A_{\max }-A\right)^{2} \times(1+M-A) \times N^{\prime}\right)+\right.\right.$ $\left.\left.\left(100 \times\left(F \times N^{\prime}-\Sigma N^{\prime}\right) / F \times N^{\prime}{ }_{\max }-\Sigma N^{\prime}\right) \times F / F_{\max }\right)^{2}\right)^{0.5} \times$ $\left(N_{\text {primary sp. }} / N_{\text {secondary sp. }}\right) \times\left(N_{\text {oceanic sp. }} / N_{\text {neritic sp. }}\right) /$ area size $) \times$ ((Number of communities $\times$ Ecological ability of species $) /$ Environmental variability)
}

The values for $D$ phylogenetic can also be introduced in this same formula by replacing the value $N^{\prime}$ in the formula for $B^{\prime}$ by $N^{\prime} / W$ or $\left(N^{\prime} \times G\right) /$ $G_{\text {first species }}$. Then not only the number of speci- mens counts, but also the phylogenetic information they carry. This method produces problems when the numbers of specimens per species are strongly different. Depending on the questions that should be solved, the use of $N / W$ should be applied or omitted as appropriate.

For the ten species and twelve faunas which were used to demonstrate the calculation of $B^{\prime}$ (see Table I), the diversity value $B^{\prime}$ was also calculated with the application of $N / W$, assuming that these ten species are phylogenetically related as presented in cladogram A, cladogram B, or cladogram C (Fig. 13). The curves presented with these cladograms show how the phylogenetic information is expressed together with the numerical diversity of species.

The curve "C" (in Fig. 13) only represents numerical diversity, or the diversity related to clado- 
gram $\mathbf{C}$. The curves $\mathbf{A}$ and $\mathbf{B}$ are higher when the numbers of species and specimens with high phylogenetic information are more numerous. This is best seen in curve $B$ that rises when the species $V$ to $\mathrm{X}$ are better represented in the samples $\mathrm{g}$ to $\mathrm{l}$.

Since the phylogenetic diversity incorporates also the higher taxa diversity, it is possible to generate an overall diversity formula in which all diversity is incorporated. It is self explanatory that there is no or nearly no area for which all the parameters are known which are needed to apply the overall formula. Therefore, the formula is only given in the Appendix and the use of more restricted formulas is advocated.

\section{The area}

So far diversity has been discussed as a value dependent on the species in an area. Some areas like neritic and oceanic areas have been given special attention. However, there are other areas that show particular characters related to diversity.

Diversity seems to increase from pole to equator (Cohen, 1986; Van Soest, 1979). "The causes for the observed N-S diversity are probably based on three major factors: climatic changes in the near past, the N-S position of the southern continents and the presence of some strong latitudinal Southern Ocean hydrographical barriers ... It can be inferred from the data presented, that most if not all holoplanktonic groups have their origin in surface waters of the lower latitudes of the oceans" (Van Soest, 1979: 111). Both above-mentioned authors look at the broad latitudinal pattern. Concerning water masses, in these low latitudes the Central water masses clearly can be considered of high phylogenetic importance, as they are the oldest "hydroplates"' known from where post-Cretaceous radiation of the oceanic pelagic could have started (Van der Spoel et al., 1990).

The neritic pelagic organisms are probably all derived from oceanic ones (Tokioka, 1979), but the speciation and radiation processes after the Cretaceous are mainly located around the IndoMalayan and Antarctic areas (Van der Spoel, 1991). These observations induced me also to give the high values to these areas in Table VIII.

Enclosed deep-sea basins like the Mediterranean and Red Sea need special attention as it is doubtful that these areas have a normal autochthonous population. Temperature and salinity in enclosed deep basins frequently deviate from the normal deep-sea conditions. The deep-sea fauna in these basins tends to live in more shallow depths (Van der Spoel \& Schalk, 1988). More drastic is the opinion: "much of this Mediterranean deep-sea fauna consists of reproductively sterile pseudopopulations that are constantly derived through larval inflow from Atlantic mother populations" given by Bouchet \& Taviani (1992: 169). Such kinds of pseudopopulations have no value for future diversity as they simply do not generate new diversity. For the ecology of a basin, they are of importance as they recirculate biomass and generate biomass for other biological components of the living world. Biologically the value is thus small but essential, especially for the ecology; for society the value is negligible, and for future diversity the diversity value of the enclosed deep-sea basin is zero.

The concept of pseudopopulations shows that in the pelagic realm, distribution of a taxon is not identical to its biological range. The distribution of a pelagic taxon is usually accepted to be composed of a biological range where the species is represented by: (1) reproducing and self-supporting populations, (2) an expatriation range where reproduction is found but no self-supporting population due to scarcity of specimens, and (3) a sterile expatriation range where no reproduction is found.

Expatriation is a normal process. The specimens in expatriation areas contribute to diversity but not to all types of diversity. Expatriated specimens contribute to ecological diversity and numerical diversity but not to genetic or phylogenetic diversity. Thus in calculating diversity for an area, the expatriated specimens should be treated differently from other specimens. Population biology in the ocean thus needs special attention with regard to diversity. The expatriation phenomenon is also a reason not to trust upon one overall formula to calculate diversity but to use separate approaches for each question and area. 


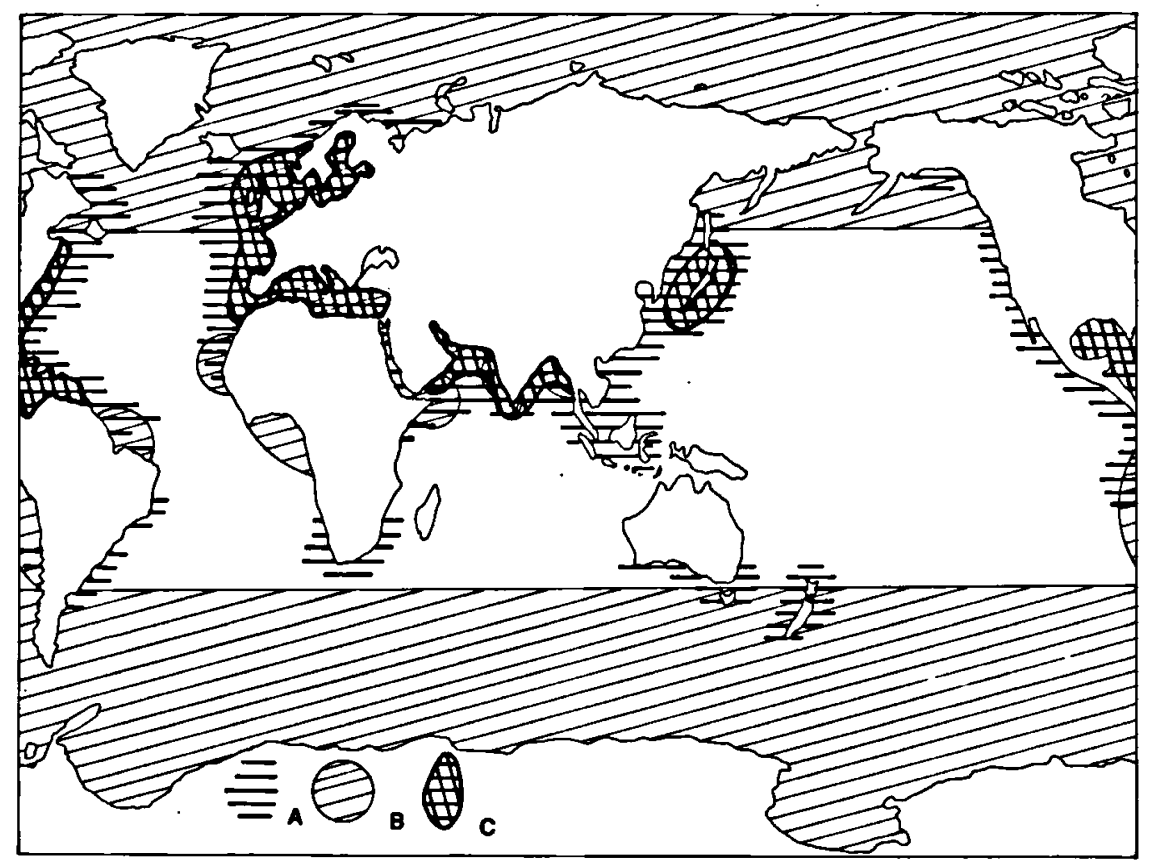

Fig. 14. Diversity of the open ocean with areas of low diversity (B) due to natural forces, and with areas of endangered diversity (A) and damaged diversity $(C)$ due to human influences.

\section{Endangered areas}

The Mediterranean and other enclosed basins have a low diversity, relative to the nearby oceans. The higher latitudes and the colder upwelling areas also have low diversity (B in Fig. 14). The whole open ocean at lower latitudes is considered of an average diversity and so is the neritic area of these latitudes. In areas of mixing, especially of mixed oceanic and neritic waters along the coast, very high diversity is recorded; this is considered an inaccurate value by the author. Only one water mass or basin should be considered at the time. By doing so the coastal waters will prove to be as diverse, or even less diverse, as the open ocean waters.

Due to fisheries and pollution, diversity has decreased in some areas. In Fig. 14 the areas are roughly indicated where diversity has been influenced (A) and really disturbed (C). Areas of major concern are those with high fishing pressure and pollution in the vicinity of densely populated coastal areas. The tropical and subtropical open ocean is the most diverse by nature and by the limit- ed pollution as shown in Fig. 14. For society the situation may be considered more bad than for nature: the areas with the primary species and primary ecosystems (cf. Beklemishev, 1971; Tokioka, 1979) and with phylogenetically original species are in the best condition, but the areas which provide society with most of the living resources are in direct danger.

When studying diversity of a local area, one can ask: do species with wide, with restricted, with disjunct, or with endemic distributions have the same importance for diversity? When diversity is calculated with the formula for $B$ and $B^{\prime}$, it becomes clear that this series of distribution types also represents a series of increasing diversity value (Fig. 11). Species have an increasing value for diversity in the following sequence: whether they can be easily, less easily, with difficulty, or cannot be, replaced by specimens from elsewhere. This approach takes into account, of course, also areas outside the one studied. When only considering samples of the area studied, it is complicated and sometimes impossible to define diversity. 
Table $V$. Data set of a less variable fauna.

\begin{tabular}{|c|c|c|c|c|c|c|c|c|c|c|c|c|}
\hline species & $\mathbf{a}$ & b & c & d & e & f & 8 & h & $\mathbf{i}$ & $\mathbf{j}$ & $\mathbf{k}$ & 1 samples \\
\hline \multicolumn{13}{|l|}{ Data } \\
\hline I & 5 & 6 & 4 & 5 & 6 & 4 & 6 & 5 & 7 & 6 & 5 & 7 \\
\hline II & 15 & 13 & 15 & 10 & 11 & 12 & 13 & 12 & 14 & 11 & 12 & 12 \\
\hline III & 4 & 5 & 3 & 5 & 3 & 6 & 4 & 3 & 7 & 3 & 6 & 4 \\
\hline IV & 4 & 6 & 5 & 7 & 6 & 5 & 7 & 5 & 5 & 6 & 5 & 7 \\
\hline $\mathbf{V}$ & 1 & $\mathbf{0}$ & 1 & 0 & 1 & 0 & 1 & 0 & 1 & 0 & 1 & 0 \\
\hline VI & 21 & 19 & 15 & 19 & 21 & 20 & 19 & 17 & 1 & 18 & 19 & 20 \\
\hline VII & 15 & 13 & 15 & 10 & 15 & 13 & 15 & 10 & 11 & 12 & 11 & 11 \\
\hline VIII & 1 & 2 & 2 & 2 & 1 & 2 & 1 & 1 & 2 & 1 & 1 & 1 \\
\hline IX & 10 & 10 & 10 & 10 & 10 & 10 & 11 & 10 & 10 & 10 & 9 & 10 \\
\hline $\mathbf{x}$ & 9 & 9 & 9 & 9 & 9 & 9 & 9 & 9 & 10 & 9 & 9 & 9 \\
\hline \multicolumn{13}{|l|}{$B$ values } \\
\hline$B$ & 28.1 & 29.8 & 55.0 & 30.7 & 18.3 & 41.0 & 25.1 & 30.1 & 3.8 & 23.2 & 25.1 & 16.6 \\
\hline$B$ & 52.1 & 35.0 & 100.1 & 12.8 & 21.5 & 24.8 & 42.5 & 40.1 & 100.1 & 24.3 & 37.7 & 24.8 \\
\hline $\boldsymbol{B}$ & 36.1 & 38.9 & 69.0 & 30.7 & 41.8 & 24.7 & 44.3 & 50.0 & 3.8 & 51.3 & 16.3 & 41.0 \\
\hline $\boldsymbol{B}$ & 36.1 & 29.8 & 40.9 & 13.7 & 18.3 & 32.8 & 15.6 & 30.1 & 25.1 & 23.2 & 25.1 & 16.6 \\
\hline $\boldsymbol{B}$ & 62.8 & 0.0 & 98.9 & 0.0 & 60.4 & 0.0 & 75.4 & 0.0 & 82.7 & 0.0 & 63.5 & 0.0 \\
\hline $\boldsymbol{B}$ & 100.1 & 90.1 & 100.1 & 90.1 & 100.1 & 90.1 & 100.1 & 90.1 & 80.6 & 90.1 & 100.1 & 90.1 \\
\hline $\boldsymbol{B}$ & 52.1 & 35.0 & 100.1 & 12.8 & 52.9 & 32.9 & 61.7 & 20.2 & 58.4 & 33.7 & 28.8 & 16.7 \\
\hline $\boldsymbol{B}$ & 60.0 & 66.5 & 83.1 & 56.5 & 57.5 & 57.3 & 73.1 & 70.0 & 66.7 & 70.1 & 60.7 & 65.5 \\
\hline $\boldsymbol{B}$ & 12.4 & 7.8 & 29.7 & 12.8 & 13.8 & 8.8 & 23.3 & 20.2 & 44.6 & 15.0 & 11.1 & 8.8 \\
\hline$B$ & 5.0 & 3.6 & 15.8 & 4.9 & 6.3 & 3.0 & 4.9 & 10.4 & 44.6 & 6.0 & 11.1 & 3.0 \\
\hline \multicolumn{13}{|c|}{$B^{\prime}$ values } \\
\hline $\boldsymbol{B}^{\prime}$ & 16.3 & 28.0 & 43.1 & 36.5 & 2.5 & 55.2 & 7.8 & 24.2 & 27.4 & 13.3 & 15.9 & 6.1 \\
\hline $\boldsymbol{B}^{\prime}$ & 71.5 & 49.9 & 100.0 & 27.2 & 45.9 & 41.5 & 63.4 & 56.2 & 100.0 & 42.5 & 58.6 & 42.3 \\
\hline $\boldsymbol{B}^{\prime}$ & 32.6 & 45.4 & 70.6 & 36.5 & 52.3 & 21.2 & 42.3 & 66.3 & 27.4 & 71.1 & 1.4 & 52.7 \\
\hline $\boldsymbol{B}^{\prime}$ & 32.6 & 28.0 & 20.7 & 6.4 & 2.5 & 36.8 & 6.0 & 24.2 & 5.9 & 13.3 & 15.9 & 6.1 \\
\hline $\boldsymbol{B}^{\prime}$ & 115.0 & 0.0 & 156.2 & 0.0 & 114.6 & 0.0 & 136.7 & 0.0 & 133.2 & 0.0 & 122.0 & 0.0 \\
\hline $\boldsymbol{B}^{\prime}$ & 100.0 & 90.0 & 100.0 & 90.0 & 100.0 & 90.0 & 100.0 & 90.0 & 132.8 & 90.0 & 100.0 & 90.0 \\
\hline $\boldsymbol{B}^{\prime}$ & 71.5 & 49.9 & 100.0 & 27.2 & 71.6 & 49.0 & 77.1 & 38.8 & 74.2 & 50.8 & 50.8 & 34.4 \\
\hline $\boldsymbol{B}^{\prime}$ & 114.5 & 123.3 & 105.9 & 109.4 & 114.2 & 106.9 & 136.4 & 138.3 & 85.9 & 142.8 & 121.6 & 143.9 \\
\hline $\boldsymbol{B}^{\prime}$ & 38.0 & 22.8 & 53.9 & 27.2 & 38.1 & 24.6 & 47.6 & 38.8 & 64.2 & 33.5 & 33.3 & 25.7 \\
\hline $\boldsymbol{B}^{\prime}$ & 29.5 & 12.1 & 42.2 & 17.2 & 29.6 & 15.0 & 28.9 & 29.0 & 64.2 & 23.7 & 33.3 & 16.2 \\
\hline \multicolumn{13}{|l|}{ Indexes } \\
\hline$B / 100$ & 4.4 & 3.4 & 6.9 & 2.7 & 3.9 & 3.2 & 4.7 & 3.6 & 5.1 & 3.4 & 3.8 & 2.8 \\
\hline$B^{\prime} / 100$ & 6.2 & 4.5 & 7.9 & 3.8 & 5.7 & 4.4 & 6.5 & 5.1 & 7.2 & 4.8 & 5.5 & 4.2 \\
\hline$m / v / 10$ & 0.2 & 0.3 & 0.2 & 0.3 & 0.3 & 0.3 & 0.2 & 0.3 & 0.2 & 0.3 & 0.2 & 0.3 \\
\hline$D$ & 2.0 & 1.8 & 2.1 & 1.8 & 2.0 & 1.8 & 2.0 & 1.9 & 2.1 & 1.8 & 2.1 & 1.8 \\
\hline$\lambda$ & 0.8 & 0.9 & 0.9 & 0.9 & 0.8 & 0.9 & 0.9 & 0.9 & 0.9 & 0.9 & 0.9 & 0.9 \\
\hline $\boldsymbol{H}$ & 2.9 & 2.9 & 2.9 & 2.9 & 2.9 & 2.9 & 2.9 & 2.9 & 3.0 & 2.9 & 2.9 & 2.9 \\
\hline$H^{\prime}$ & 6.4 & 6.4 & 6.3 & 6.3 & 6.4 & 6.3 & 6.4 & 2.9 & 3.0 & 6.2 & 3.0 & 2.9 \\
\hline$J^{\prime}$ & 1.4 & 1.3 & 1.4 & 1.3 & 1.4 & 1.3 & 1.4 & 1.2 & 1.4 & 1.2 & 1.4 & 1.3 \\
\hline
\end{tabular}

From Table $\mathrm{V}$ the values $B$ and $B^{\prime}$ clearly have a discriminating value also for samples from a rather homogeneous, mixed fauna, as the relative numbers of specimens influence the outcome. The other indexes are less discriminating (Fig. 15).

\section{Marine diversity of the total world ocean}

When studying the diversity of a large part of the oceans or of all oceans, the best results are to be expected when widely spread species get attention so 


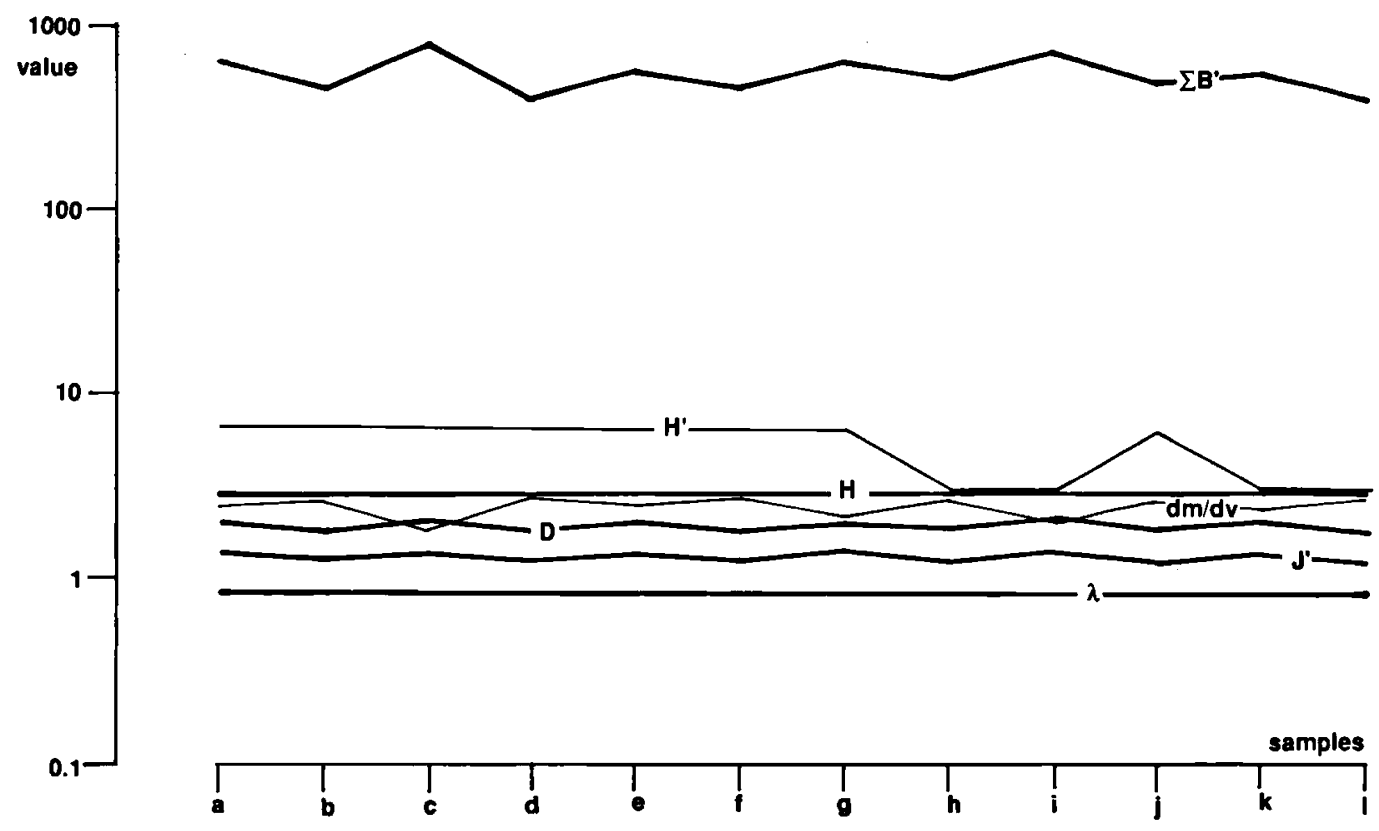

Fig. 15. Curves of the diversity values comparable to the curve in Fig. 9 for a fauna with very low diversity (cf. Table V).

that the numbers generated for the different areas are comparable. The pteropods Clio pyramidata, Limacina inflata (D'Orbigny, 1836) and the Hydromedusae Pantachogon haeckeli Maas, 1893 and Rhopalonema velatum Gegenbaur, 1856 are good examples of widespread species. Common species like these four are relatively tolerant. Their absence and presence tells us more about the environment than rare species do. Moreover, sampling of the pelagic is a difficult task as all sampling techniques suffer from great inaccuracy. The statement by Seapy (1991: 45): "Ten replicate tows would be needed to sample the four most abundant species" of heteropods is one of the many complaints about the difficulties of sampling. In studying pelagic diversity, an important topic should be "sampling".

\section{Marine diversity on a restricted location}

In a small locality, a smaller variation in diversity is expected than in larger ones where homogeneity increases, but, as expressed with $B$ or $B^{\prime}$ values (Fig. 15, Table V), differences are visible. A problem arises when comparing different smaller areas, especially when sampling techniques are different, which is frequently the case. Besides this mathematical problem a large faunal difference is to be expected.

When at different places different kinds of samples are taken, it is usually not possible to compare the results with known diversity indexes. With the formulae for $B$ or $B^{\prime}$, it is possible to make counts for each single sample when the formula is simplified to:

$$
B^{\prime \prime}=\left(\left(100 \times\left(F \times N^{\prime}-\Sigma N^{\prime}\right) /\left(F \times N^{\prime}{ }_{\max }-\Sigma N^{\prime}\right)^{2}+N^{\prime}\right)^{0.5}\right.
$$

The values obtained usually give acceptable indexes independent of the sample size and the type of sampling (see Table VI). With this modified formula, the contribution of a single species to the diversity stays measurable.

The faunal difference between two areas can be of two types, viz. (1) the two areas are characterized by species that replace each other in the ecosystems or (2) the two areas are provided with completely different systems and species. When comparing the Atlantic Ocean west of Ireland and the Mediterranean south of Italy, the areas are of the first type. Many Atlantic species are in the 
Table VI. Comparison of the diversity indexes when calculated for the hypothetical samples separately and in relation to each other.

\begin{tabular}{|c|c|c|c|c|c|c|c|c|}
\hline speci & 1 & 2 & 3 & 4 & 5 & 6 & 7 & 8 samples \\
\hline \multicolumn{9}{|c|}{ Data } \\
\hline I & 4 & 5 & 1 & 0 & 0 & 0 & & \\
\hline II & 5 & 4 & 2 & 0 & 0 & 0 & & \\
\hline III & 7 & 3 & 1 & 0 & 0 & 7 & & \\
\hline IV & 4 & 4 & 1 & 0 & 0 & 4 & & \\
\hline $\mathbf{V}$ & 3 & 7 & 2 & 0 & 4 & 3 & & 4 \\
\hline VI & 1 & 7 & 2 & 0 & 31 & 1 & & 5 \\
\hline VII & 7 & 8 & 3 & 7 & 7 & 7 & 7 & 7 \\
\hline VIII & 8 & 12 & 4 & 8 & 8 & 8 & 8 & 4 \\
\hline IX & 12 & 19 & 4 & 12 & 12 & 12 & 12 & 3 \\
\hline $\mathbf{X}$ & 19 & 1 & 1 & 19 & 19 & 19 & 19 & 1 \\
\hline \multicolumn{9}{|c|}{ Diversity index calculated for the samples separately } \\
\hline$B^{\prime \prime}$ & 306.4 & 306.4 & 495.4 & 87.6 & 160.0 & 230.0 & 87.6 & 164.2 \\
\hline$B^{\prime \prime \prime}$ & 440.9 & 440.9 & 552.4 & 95.9 & 192.4 & 331.4 & 95.9 & 212.8 \\
\hline \multicolumn{9}{|c|}{ Diversity index calculated for the samples taken together as if they were related } \\
\hline $\boldsymbol{B}$ & 376.7 & 375.7 & 522.5 & 87.6 & 167.9 & 264.5 & 87.6 & 175.7 \\
\hline$B^{\prime}$ & 454.9 & 453.8 & 561.3 & 95.9 & 192.9 & 337.8 & 95.9 & 214.2 \\
\hline \multicolumn{9}{|c|}{ Differences between the two methods } \\
\hline $\boldsymbol{B}$ & 70.3 & 69.4 & 27.1 & 0 & 7.9 & 34.6 & 0 & 11.4 \\
\hline$B^{\prime}$ & 14.0 & 12.8 & 8.8 & 0 & 0.5 & 6.4 & 0 & 1.3 \\
\hline
\end{tabular}

Mediterranean replaced by other species, subspecies, or forms. Many examples of this replacement are published, e.g. for fishes (Badcock, 1981) and for molluscs and chaetognaths (Furnestin, 1970; 1979). In the pelagic realm most faunal differences between areas are of the first type. Even comparing oceanic and neritic waters usually means comparing ecosystems in which the species replace each other.

However, comparison of the faunas from shallow layers and the deep sea, or from cold waters and warm waters, shows that these are areas of the second type with completely different species and ecosystems. When studying this kind of area, with completely different ecology and history, it is advised not to use the $B^{\prime \prime}$ values for separate samples when making a comparison. The numerical values may be correct, but the ecological, historical, and phylogenetical diversity of these faunas is completely different and not expressed in the $B^{\prime \prime}$ values in this case. Here one should consider numerical and other diversities either separately or one can use the overall formula given in the Appendix.

\section{The taxon}

In calculating diversities (species diversity), one should always avoid becoming restricted to one small taxonomic group, as many groups do not occur in all parts of the ocean. Heteropoda for example are usually not found north of $45^{\circ} \mathrm{N}$, and pelagic nemerteans are not found above $1000 \mathrm{~m}$ depth, to give two examples. These examples demonstrate that for certain areas certain groups will give deviating diversities. Consideration of higher taxa is only allowed when determining higher taxa diversity.

Groups with large diversity contribute more to diversity than those with small diversity; groups with wide-spread, common species contribute to diversity over greater areas than groups with endemic and rare species, which contribute more to local diversity.

The formula $N(x)=a x^{-b}$ presented by Minelli et al. (1991) could be a useful tool to employ in taxonomic groups to measure the within-taxon type of diversity, based on the species body size, species 
Table VII. Items that can generate priorities with regard to the different (in first column) diversity studies.

\begin{tabular}{|c|c|c|c|}
\hline & \multirow[b]{2}{*}{$\begin{array}{l}\text { knowledge } \\
\text { needed }\end{array}$} & \multicolumn{2}{|c|}{ endangered with } \\
\hline & & $\begin{array}{l}\text { danger for } \\
\text { mankind }\end{array}$ & $\begin{array}{l}\text { biological } \\
\text { danger }\end{array}$ \\
\hline numerical & $\mathbf{A}$ & I & 1 \\
\hline ecological & B & II & 2 \\
\hline genetical & C & & 3 \\
\hline historical & D & & 4 \\
\hline phylogenetic & $\mathbf{E}$ & & 5 \\
\hline
\end{tabular}

abundance, species numbers, or species relations. Actual application of the formula, however, requires a perfect and worldwide knowledge on the maximum or average body size, average abundance, and taxonomy of the species - a requirement usually not fulfilled.

\section{An inventory}

Pelagic diversity in the sense as defined in this paper (the numerical, historical, ecological, and phylogenetic contribution of specimens to the present and future diversity in the environment) has received little or no attention in the past. Projects to study especially pelagic diversity have never been organized. Almost all research in the past concentrated on pelagic ecology or faunistics. Some studies have demonstrated the ecological and taxonomic uniqueness of areas like: the oxygen minimum of the East Pacific (e.g., Johnson, 1982), upwelling areas (Badcock, 1981; Hilgersom \& Van der Spoel, 1987), the Indo-Malayan area (Brinton, 1975; Fleminger, 1986), Antarctic waters (Van der Spoel, 1991), and neritic waters (Tokioka, 1979). The phylogenetic and historical uniqueness of the Antarctic, and Indo-Malayan, Central waters has been shown by Van der Spoel et al. (1990). The importance of areas, mostly neritic, for fisheries is discussed in many papers, and some endangered species like whales and seals have received considerable attention.

\section{What diversity is known?}

Publications on pelagic diversity are hard to find, but much knowledge remains hidden in museums and other collections. Museum collections are usually so organized that they contain a few specimens of most species from one or more areas. Thus with this kind of material, a study can be made of the presence or absence of species in an area over a period of several years. Data like those presented in Figs. 7 and 8 can be obtained from museum collections. Collections from expeditions, fisheries research projects, and the like are even more promising for diversity studies, as usually entire samples and sample series are still preserved. Even from older expeditions like the Dana, Galathea, Atlantide, and Siboga Expeditions, the samples are preserved. These collections may well add to our knowledge of diversity of an area in a certain period, provided that the already-studied parts of the samples can be traced as specimens or literature data. As expeditions give a picture of the diversity in the past, they have to be considered of great importance. Surveys of more recent age can also contribute, as shown by Kouwenberg \& Razouls (1990) who compared Mediterranean surveys of plankton made in the 1960's and in the 1980's. Maybe most of our knowledge on pelagic diversity is thus still hidden on the shelves of collections.

\section{Which diversity has to be studied?}

Where do we have to start with the study of pelagic diversity when almost nothing is known? Indeed, what are the priorities? There are two reasons for giving priority, viz. the need of knowledge in general, and the need to protect endangered areas or groups. Endangered areas or groups can be crucial for human society as living resources are affected or a danger for nature as the natural generation of diversity, in the evolution process, is affected. The priority we select can be derived from the consideration and analysis of numerical, ecological, genetical, historical, and phylogenetic diversity. The different factors are given in Table VII. 
Table VIII. Priority calculations based on the items of Table VII.

The numbers are generated by totalizing as follows: for columns $\mathbf{A}$ to $\mathrm{E}$, small interest $=1$, moderate interest $=2$, great interest $=3$, more study needed $=1$, and much study needed $=2$; and for columns I-II and columns 1-5 by indicating: slightly endangered $=1$, moderately endangered $=2$, strongly endangered $=3$.

\begin{tabular}{|c|c|c|c|c|c|}
\hline & & A B C D E & I II & 12345 & Total priority \\
\hline OCEANIC WATERS & Arctic & 11222 & & & 8 \\
\hline & Antarctic & 55555 & 1 & 1 & 27 \\
\hline & Cold & $\begin{array}{lll}1 & 1 & 22\end{array}$ & 1 & 1 & 8 \\
\hline & Temperate & 1222 & 11 & 11 & 11 \\
\hline & Subtropical & 44344 & 11 & 11111 & 26 \\
\hline & Tropical & 45455 & 11 & 22111 & 32 \\
\hline & ndo-Malayan & 55555 & 22 & 32222 & 40 \\
\hline & Iediterranean & 11222 & 33 & 322 & 21 \\
\hline & Red Sea & 11432 & 21 & 221 & 19 \\
\hline & Caribbean & 22433 & 21 & 21 & 20 \\
\hline Central & tlantic Ocean & 55555 & 1 & 22111 & 33 \\
\hline Waters & Indian Ocean & 44444 & 1 & 22111 & 28 \\
\hline & acific Ocean & 55555 & 1 & 22111 & 33 \\
\hline Terminal & tlantic Ocean & 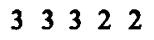 & 21 & 21 & 19 \\
\hline Waters & Indian Ocean & 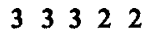 & 11 & 1 & 16 \\
\hline & acific Ocean & 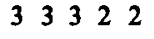 & 11 & 1 & 16 \\
\hline NERITIC WATERS & Arctic & 222222 & 1 & 1 & 12 \\
\hline & Antarctic & 55555 & 1 & 11 & 28 \\
\hline & Cold & 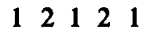 & 1 & 1 & 9 \\
\hline & Temperate & 44443 & 33 & 33321 & 37 \\
\hline & Subtropical & 44344 & 22 & 33222 & 35 \\
\hline & Tropical & 44344 & 11 & 22222 & 31 \\
\hline & ndo-Malayan & 55555 & 22 & 33333 & 44 \\
\hline & Iediterranean & $\begin{array}{lllll}2 & 2 & 3 & 3 & 3\end{array}$ & 33 & 33321 & 31 \\
\hline & Red Sea & 22333 & 22 & 22211 & 25 \\
\hline & Caribbean & $\begin{array}{lllll}2 & 2 & 1 & 2 & 2\end{array}$ & 21 & 21 & 15 \\
\hline
\end{tabular}

The priorities for research and monitoring of the marine biotas of the various basins of the ocean are given in Table VIII, corresponding to the factors given in Table VII. The higher the total priority, the greater and more urgent is the attention that should be paid to a particular area. The areas that should be studied with highest priorities are: the IndoMalayan neritic and oceanic waters, the neritic temperate and subtropical waters, the tropical waters, and especially the Atlantic and Pacific Central waters.

To follow changes and developments in diversity, monitoring programs on a global and on local scale are needed. It seems most logic to urgently develop the needed monitoring programs, following priorities such as those in Table VIII.

\section{Summary}

Diversity can be considered as necessary for, and produced by, evolution, otherwise it would be no evolving process. It is essential to preserve "life", and necessary for humans since the diversity in nature warrants the presence of living resources. Biodiversity crises have made society aware of the appreciation we must have for diversity. This appreciation can hardly be expressed by a precise number. However, the quality of diversity from a biological point of view can be given a value, i.e., how diverse is nature at a certain place and time. All taxa at all levels certainly contribute to diversity. By the different nature of taxa of different levels, the high levels (higher taxa diversity), the species and genus 
level (species diversity) and the lower levels (subspecific diversity) each show a different type of diversity.

Another possibility for a more detailed approach to diversity is to distinguish between numerical diversity, ecological diversity, genetic diversity, historical diversity, and phylogenetic diversity, as each approach gives us another insight in the value of diversity. Different indexes for diversity are available, but the most indicative index seems to be the index $B$ that gives a value to each species which expresses its contribution to the total numerical diversity. The recognition of ecological, genetic, historical, and phylogenetic diversity is still in its infancy, and only a provisional accounting for these different diversities is now possible.

As diversity is usually mentioned in relation to human influences, one should realize that diversity also fluctuates in response to natural forces. These diversity fluctuations are mainly opposite in value to biomass fluctuations.

Each area has its typical diversity and human influences have decreased this diversity, especially in neritic areas, so that these areas require particular attention. Of special interest from a scientific point of view are the areas where evolution seems to be most successful, viz.: the Central waters and the Indo-Malayan area.

Attention can also be given to the typical diversity of a taxonomic group. Each group has been shown to have its own specific diversity that can be defined by a non-linear, fractal equation. This group-specific diversity is expressed in the number and phylogenetic relation of the taxa, but also in their body size and abundance. So biomass fluctuations will have different effects on groups with different in-group diversity.

Evolution seems to have a non-linear nature (Nicolis, 1992). Population growth and thus biomass fluctuations, but also diversity in a group, and the diversity fluctuations seem to be determined by non-linear processes too. Prediction of diversity will be as difficult to make as the prediction of evolution. We can be only sure of what minimally reduces the diversity as taxa disappear. As concluded from Table VIII, certain areas in the ocean should get urgent attention for scientific or for practical reasons. However, such special attention alone will be insufficient to solve problems. It is also necessary to change our attitude (Nicolis, 1992), realizing that the processes governing diversity are non-linear in the majority of cases. This change in attitude may best start by appraising: (1) the value of diversity of the ocean for human society and (2) the value of each single species for the different kinds of diversity like genetical, historical, ecological, and phylogenetic diversity, rather than merely calculating the simple mathematics of species diversity.

\section{Acknowledgements}

The first draft of this paper was carefully commented on by Drs. M. van Couwelaar and F.F.J.M. Pieters to whom the author is thankful. The essential corrections and contributions to the presentation of this paper by Dr. D. Krause are highly appreciated.

\section{References}

Badcock, J., 1981. The significance of meristic variation in Benthosema glaciale (Pisces, Myctophoidei) and of the species distribution off northwest Africa. Deep-Sea Res., 28A(12): 1477-1491.

Beklemishev, C.W., 1971. Distribution of plankton as related to micropalaeontology. In: B.M. Funnel \& W.R. Riedel (eds.), The micropalaeontology of oceans: 75-87 (Cambridge Univ. Press, London).

Bleeker, J. \& S. van der Spoel, 1988. Medusae of the Amsterdam Mid North Atlantic Plankton Expeditions (1980-1983) with description of two new species. Bijdr. Dierk., 58(2): 227-258.

Bouchet, P. \& M. Taviani, 1992. The Mediterranean deep-sea fauna: pseudopopulations of Atlantic species? Deep-Sea Res., 39(2A): 169-184.

Brinton, E., 1975. Euphausiids of Southeast Asian waters. Naga Rep., 4(5): 1-287.

Buchlin, A., 1986. The genetic structure of zooplankton populations. In: A.C. Pierrot-Bults, S. van der Spoel, B.J. Zahuranec \& R.K. Johnson (eds.), Pelagic biogeography. Unesco tech. Pap. mar. Sci., 49: 35-41.

Caldeira, K. \& J.F. Kasting, 1992. The life span of the biosphere revisited. Nature, 360(6406): 721-723.

Carillo, B.G.E., C.B. Miller \& P.H. Wiebe, 1974. Failure of interbreeding between Atlantic and Pacific populations of the marine calanoid copepod Acartia clausi Giesbrecht. Limnol. Oceanogr., 19(3): 452-458. 
Cohen, D.M., 1986. Latitudinal variation in diversity and biomass in IKMT catches from the western Indian Ocean. In: A.C. Pierrot-Bults, S. van der Spoel, B.J. Zahuranec \& R.K. Johnson (eds.), Pelagic biogeography. Unesco tech. Pap. mar. Sci., 49: 54-59.

Fleminger, A., 1986. The pleistocene equatorial barrier between the Indian and Pacific oceans and a likely cause for Wallace's line. In: A.C. Pierrot-Bults, S. van der Spoel, B.J. Zahuranec \& R.K. Johnson (eds.), Pelagic biogeography. Unesco tech. Pap. mar. Sci., 49: 84-97.

Furnestin, M.-L., 1970. Chaetognathes des campagnes danoises dans l'Atlantique nord. Notes écologiques et biogéographiques. Dana Rep., 80: 3-7.

Furnestin, M.-L., 1979. Aspects of the zoogeography of the Mediterranean plankton. In: S. van der Spoel \& A.C. PierrotBults (eds.), Zoogeography and diversity of plankton: 191253 (Bunge, Utrecht).

Haury, L.R., J.J. McGowan \& P.H. Wiebe, 1977. Patterns and processes in the time-space scales of plankton distribution. In: J.H. Steele (ed.), Spatial pattern in plankton communities: 227-328 (Plenum Press, New York \& London).

Hilgersom, P.C.J. \& S. van der Spoel, 1987. East-west variation in Diacria off northwestern Africa. Malac. Rev., 20: 97-104.

Humphries, C.J. \& L.R. Parenti, 1986. Cladistic biogeography: i-xii, 1-98 (Clarendon Press, Oxford).

Johnson, R.K., 1982. Fishes of the families Evermannellidae and Scopelarchidae: systematics, morphology, interrelationships, and zoogeography. Fieldiana (Zool., N.S.), 12: i-xiii, 1-252.

Kouwenberg, J. \& C. Razouls, 1990. The incidence of environmental factors on the evolution of copepod populations in the "Golfe du Lion" during the period 1986-88 in comparison with the period 1957-64. Bull. Soc. zool. Fr., 115(1): 23-36.

Lasserre, P., 1992. The role of biodiversity in marine ecosystems. In: O.T. Solbrig, H.M. van Emden \& P.G.W.J. van Oordt (eds.), Biodiversity and global change: 105-130 (Intern. Union biol. Sci., Paris).

Lovelock, J.E. \& M. Whitfield, 1982. Life span of the biosphere. Nature, 296(5857): 561-563.

Margalef, D.R., 1951. Diversidad de especies en las comunidades naturales. Publnes Inst. Biol. apl. Barcelona, 9: 5-27.

Margalef, D.R., 1957. La teoría de la información en ecología. Memorias R. Acad. Cienc. Artes Barcelona, 23: 373-449.

Margalef, D.R., 1958. Temporal succession and spatial heterogeneities in phytoplankton. In: A. Buzzati-Traverso (ed.), Perspectives in marine biology: 323-349 (Univ. California Press, Berkeley).

May, R.M., 1992. Past efforts and future prospects towards understanding how many species there are. In: O.T. Solbrig, H.M. van Emden \& P.G.W.J. van Oordt (eds.), Biodiversity and global change: 71-81 (Intern. Union biol. Sci., Paris).

Mayr, E., 1963. Animal species and evolution: i-xiv, 1-797 (Belknap Press Harvard Univ. Press, Cambridge Mass.).

Minelli, A., G. Fusco \& S. Sartori, 1991. Self-similarity in biological classifications. Biosystems, 26: 89-97.

Nelson, G. \& P. Ladiges, 1990. Biodiversity and biogeography. J. Biogeogr., 17: 559-560.
Nicolis, G., 1992. Dynamical systems, biological complexity and global change. In: O.T. Solbrig, H.M. van Emden \& P.G.W.J. van Oordt (eds.), Biodiversity and global change: 21-32 (Intern. Union biol. Sci., Paris).

Omori, M. \& T. Ikeda, 1984. Methods in marine zooplankton ecology: i-xiii, 1-332 (Wiley, New York etc.).

Pielou, E.C., 1966. The measurement of diversity in different types of biological collections. J. theor. Biol., 13: 131-144.

Pierrot-Bults, A.C. \& S. van der Spoel, 1979. Speciation in macrozooplankton. In: S. van der Spoel \& A.C. Pierrot-Bults (eds.), Zoogeography and diversity of plankton: 144-167 (Bunge, Utrecht).

Reid, J.L., E. Brinton, A. Fleminger, E.L. Venrick \& J.A. McGowan, 1976. Ocean circulation and marine life. In: $\mathbf{H}$. Charnock \& G. Deacon (eds.), Advances in oceanography: 65-130 (Plenum Press, New York/London).

Seapy, R.R., 1991. Sampling requirements for epipelagic heteropod molluscs. Amer. malacol. Bull., 8(1): 45-52.

Simpson, E.H., 1949. Measurement of diversity. Nature, Lond., 163(4148): 688.

Soest, R.W.M. van, 1979. North-south diversity. In: S. van der Spoel \& A.C. Pierrot-Bults (eds.), Zoogeography and diversity of plankton: 103-111 (Bunge, Utrecht).

Spoel, S. van der, 1967. Euthecosomata, a group with remarkable developmental stages (Gastropoda, Pteropoda): 1-376 (J. Noorduijn \& Zn, Gorinchem).

Spoel, S. van der, 1991. Hydromedusan distribution patterns. Hydrobiologia, 216/217: 489-496.

Spoel, S. van der \& J. Bleeker, 1991. Distribution of Myctophidae (Pisces, Myctophiformes) during the four seasons in the mid North Atlantic. Bijdr. Dierk., 61(2): 89-106.

Spoel, S. van der, J. Bleeker \& H. Kobayasi, 1993. From Cavolinia longirostris to twenty-four Diacavolinia taxa, with a phylogenetic discussion (Mollusca, Gastropoda). Bijdr. Dierk., 62(3): 127-166.

Spoel, S. van der \& R.P. Heyman, 1983. A comparative atlas of zooplankton. Biological patterns in the oceans: 1-186 (Bunge, Utrecht).

Spoel, S. van der, A.C. Pierrot-Bults \& P.H. Schalk, 1990. Probable Mesozoic vicariance in the biogeography of Euphausiacea. Bijdr. Dierk., 60(3/4): 155-162.

Spoel, S. van der \& P.H. Schalk, 1988. Unique deviations in depth distribution of the deep-sea fauna. Deep-Sea Res., 35(7A): 1185-1193.

Tokioka, T., 1979. Neritic and oceanic plankton. In: S. van der Spoel \& A.C. Pierrot-Bults (eds.), Zoogeography and diversity of plankton: 126-143 (Bunge, Utrecht).

Vane-Wright, R.I., C.J. Humphries \& P.H. Williams, 1991. What to protect? Systematics and the agony of choice. Biol. Conserv., 55(3): 235-254.

Weinberg, S., 1992. Découvrir la Méditerranée: 1-352 (Éd. Nathan, Paris).

Wilson, E.O., 1992. The diversity of life: 1-424 (Belknap Press of Harv. Univ. Press, Cambridge Mass.).

Received: 18 May 1993

Accepted: 16 November 1993 
Appendix. The overall formula for the diversity with the factors defined so that all kinds of diversity are represented in one formula.

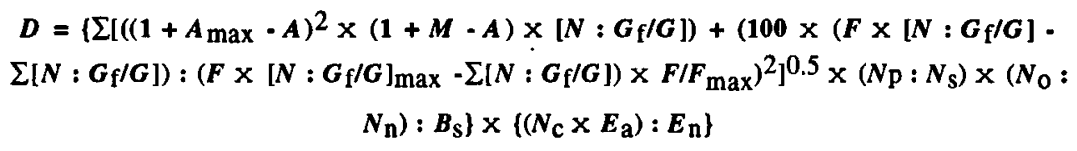

Abbreviations:

$A=$ number of samples in which the smallest genetical distinct group is found.

$A_{\max }=$ maximum value of $A$ for the series of samples studied.

$B_{\mathrm{S}}=$ area size.

$D=$ the overall diversity.

$E_{\mathrm{a}}=$ ecological ability of species.

$E_{\mathbf{n}}=$ Environmental variability.

$F=$ number of the smallest genetically distinct group in the sample.

$F_{\max }=$ number of the smallest genetically distinct groups in the sample most rich in smallest genetically distinct groups.

$G=$ the number of taxonomic groups to which a species belongs.

$G_{f}=$ the maximum number of taxonomic groups to which a sampled species can belong.

$M=$ total number of samples in the study.

$N=$ the yearly number of specimens of the smallest genetically distinct group in the sample.

This may be replaced in the formula by $\log (1+$ yearly number of specimens of the smallest genetically distinct group in the sample).

$N_{\mathrm{C}}=$ the yearly number of communities.

$N_{\mathrm{n}}=$ the total numerical diversity of neritic species in the community.

$N_{\mathrm{O}}=$ the total numerical diversity of oceanic species in the community.

$N \mathrm{p}=$ the total numerical diversity of primary species in the community.

$N_{\mathrm{S}}=$ the total numerical diversity of secondary species in the community. 